Florida International University FIU Digital Commons

\title{
Efficacy and Implementation of Automated Essay Scoring Software in Instruction of Literacies to High Level ELLs
}

Aaron J. Alvero

Florida International University, aaronjalvero@gmail.com

DOI: 10.25148 /etd.FIDC000756

Follow this and additional works at: https://digitalcommons.fiu.edu/etd

Part of the Bilingual, Multilingual, and Multicultural Education Commons, Curriculum and Instruction Commons, Curriculum and Social Inquiry Commons, Educational Assessment, Evaluation, and Research Commons, Educational Methods Commons, Instructional Media Design Commons, International and Comparative Education Commons, and the Secondary Education and Teaching Commons

\section{Recommended Citation}

Alvero, Aaron J., "Efficacy and Implementation of Automated Essay Scoring Software in Instruction of Literacies to High Level ELLs" (2016). FIU Electronic Theses and Dissertations. 2569.

https://digitalcommons.fiu.edu/etd/2569 


\title{
FLORIDA INTERNATIONAL UNIVERSITY
}

Miami, Florida

\section{EFFICACY AND IMPLEMENTATION OF AUTOMATED ESSAY SCORING} SOFTWARE IN INSTRUCTION OF LITERACIES TO HIGH LEVEL ELLS

\author{
A thesis submitted in partial fulfillment of \\ the requirements for the degree of \\ MASTER OF SCIENCE \\ in \\ FOREIGN LANGUAGE EDUCATION \\ by \\ Aaron J. Alvero
}


To: Dean Michael R. Heithaus

College of Arts, Sciences and Education

This thesis, written by Aaron J. Alvero, and entitled Efficacy and Implementation of Automated Essay Scoring Software in Instruction of Literacies to High Level ELLs, having been approved in respect to style and intellectual content, is referred to you for judgment.

We have read this thesis and recommend that it be approved.

$\begin{array}{r}\text { Maria Lovett } \\ \hline \text { Kyle Perkins } \\ \hline \text { Eric Dwyer, Major Professor }\end{array}$

Date of Defense: July 7, 2016

The thesis of Aaron J. Alvero is approved.

Dean Michael R. Heithaus

College of Arts, Sciences and Education

Andrés G. Gil

Vice President for Research and Economic Development and Dean of the University Graduate School

Florida International University, 2016 


\section{ACKNOWLEDGMENTS.}

I would like to extend my thanks and appreciation to the friends, family, and colleagues that made this all possible. Without the help of the students in the project as well as Elijah, Claude, Samir, Steven, Jessica, Davonte, and many others, I would not have had the motivation to push through.

Without my friends, especially Zac, Jeff, Tom Guthrie, Dada, and many others, I would be missing out on the immeasurable positivity that they have gifted me, the same positivity that has helped me become so determined to spend my life helping other people.

Without my mentors, especially Dr. Dwyer, Dr. Perkins, Dr. Lovett, Dr. Russo from the University of Miami, and Liesl Picard from FIU LACC, I would not have had the role models I needed to become the kind of person I would be proud to know. And without the love and support of my wife Kathy, I do not care to know where I would be. 


\title{
ABSTRACT OF THE THESIS \\ EFFICACY AND IMPLEMENTATION OF AUTOMATED ESSAY SCORING IN INSTRUCTION OF LITERACIES TO HIGH LEVEL ELLs
}

by

\author{
Aaron J. Alvero \\ Florida International University, 2016 \\ Miami, Florida \\ Professor Eric Dwyer, Major Professor
}

This thesis explored the integration of automated essay scoring (AES) software into the writing curriculum for high level ESOL students (levels 3, 4, and 5 on a 1-5 scale) at a high school in Miami, Fl. Issues for Haitian Creole speaking students were also explored. The Spanish and Haitian Creole speaking students were given the option to write notes, outlines, and planning sheets in their L1.

After using AES in the middle of the writing process as a revision assistant tool, 24 students responded to a Likert Scale questionnaire. The students responded positively to the AES based on the results of the Likert scale questionnaire: $71 \%$ responded "agree" and "strongly agree" to the question "Other students would benefit from using writing software before handing in a final draft." Also, the majority reported that they valued teacher feedback. None of the students chose to use their L1 to write notes/outlines. 


\section{TABLE OF CONTENTS}

PREFACE

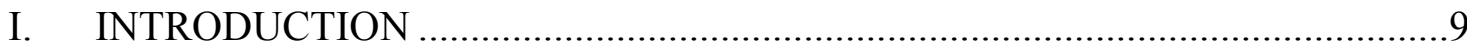

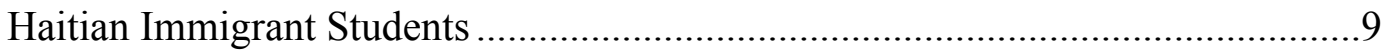

Linguistic Bases for ESOL Students in Miami.................................................12

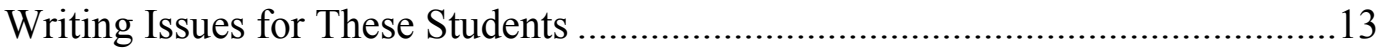

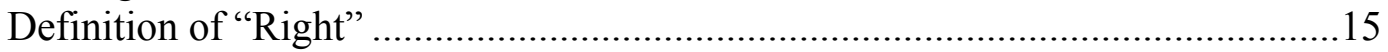

Self-Efficacy and Agency in the Writing of High School Students ......................15

Current and Future Use of Automated Essay Scoring Software.............................18

Conceptual Framework and Research Questions ...............................................20

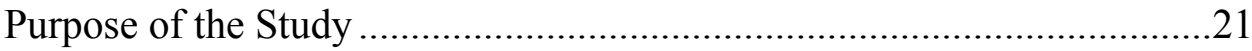

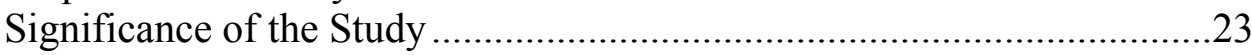

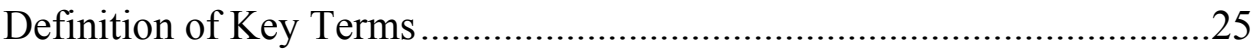

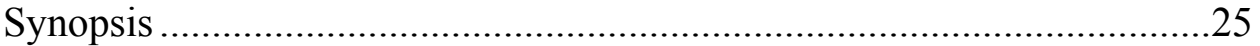

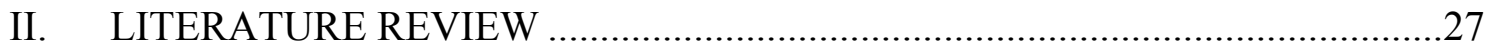

Introduction and Basic Issues for ELLs.........................................................27

Current and Future Use of AES and Other Technologies Pertaining to Literacy..29

Conjunctive Problems for ELLs and AES Software..............................................33

Technology and Issues with the Writing Process ....................................................35

Self-Efficacy and Increased Agency in Writing for High School Students............39

Related Potential Approaches to Improve Student Writing.....................................42

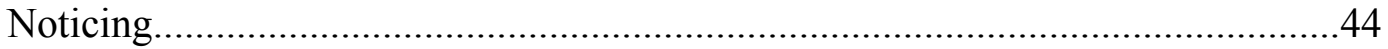

Self-Efficacy in High School Writing ...............................................................45

Issues of Linguistic Bases for High Level ESOL Students ....................................46

Affective and Social Barriers and the Use of Home Languages and

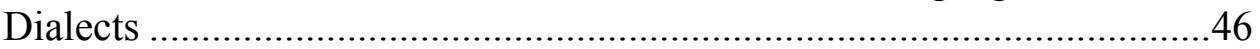

Summary and Suggestions.........................................................................4

Review of Haitian Creole .............................................................................52

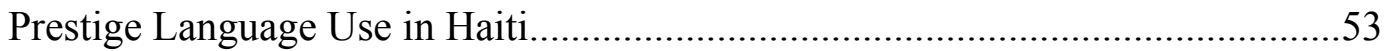

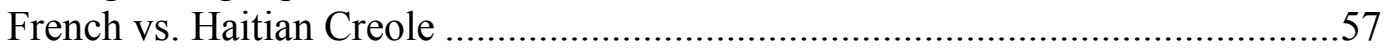

Accounting for Home Language and Dialect …………....................................59

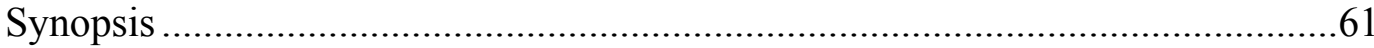

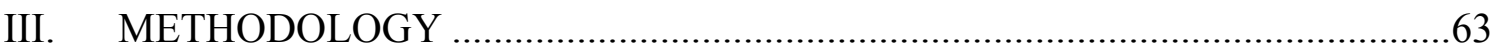

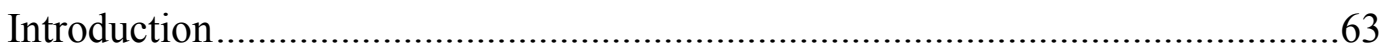

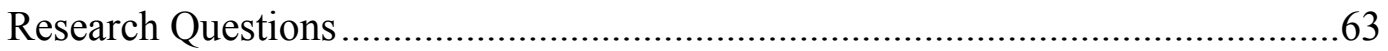

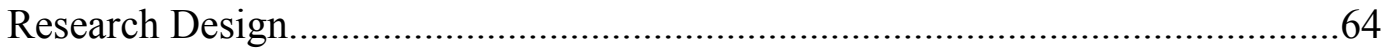

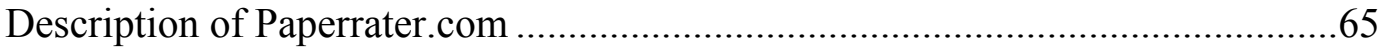


Population and Sample …………………......................................................69

Structure of My Class and Implementation of Project...............................69

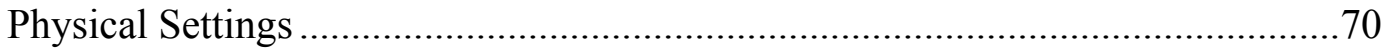

Description of the Participants..........................................................................

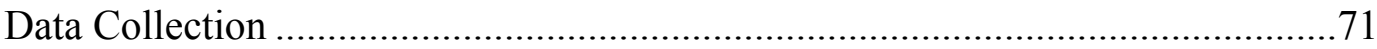

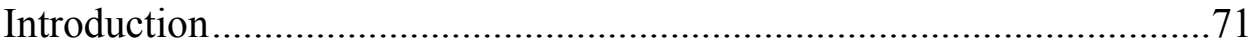

Coding the Questionnaire ……………………………...........................73

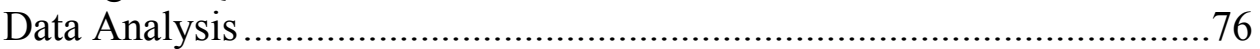

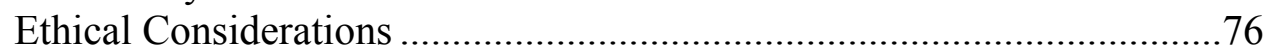

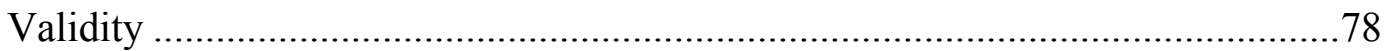

Role of the Researcher .....................................................................................

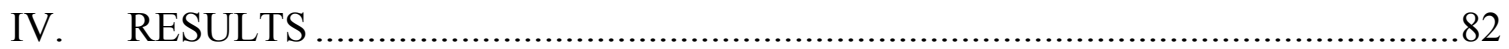

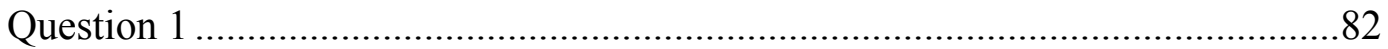

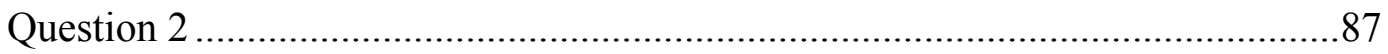

General Considerations Based on Questionnaire Results ......................................8

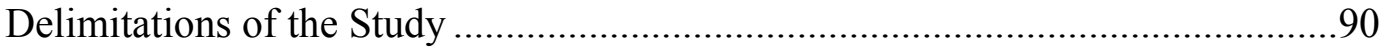

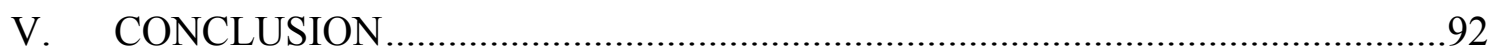

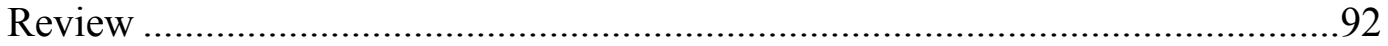

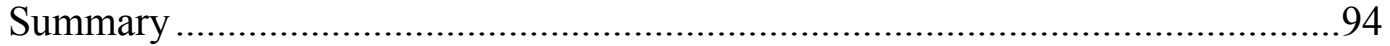

Discussion and Potential Future Experimental Framework..................................96

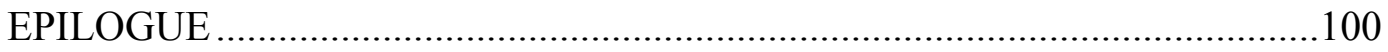

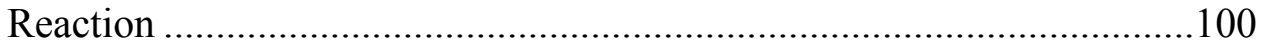

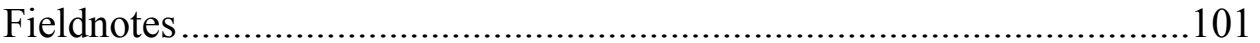

Environment and Accountability ...........................................................102

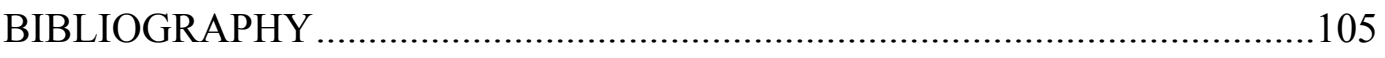

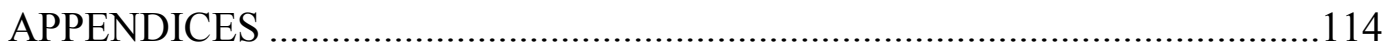

$\mathrm{CV}$ 


\section{LIST OF FIGURES}

FIGURES

PAGE

1. Maps Outlining North Miami, Little Haiti, and the Biscayne Corridor (Major Haitian Communities of Miami-Dade County) .10

2. Positive and Negative Aspects of AES Software (Blood 2011)

3. Three-Pronged Conceptual Framework

4. Pro/Con Handout from Lippincott and Fuentes-Anderson at the TESOL International Conference 2015 (Used with permission) ..........................................66

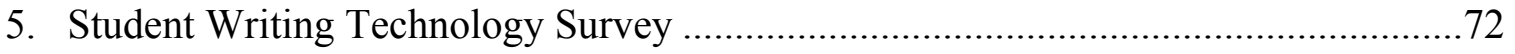

6. Each of the 19 Questions in the "Student Writing Technology Survey"....................75

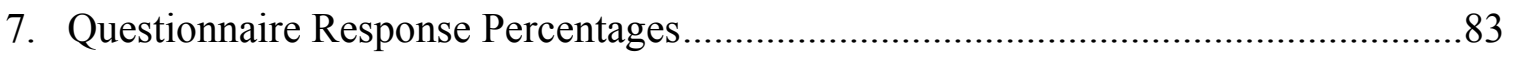

8. Chart for Possible Experiment with AES Software ..........................................97 
"Salope! You all see what it's like without roots in this world?"

—Derek Walcott, Omeros 


\section{PREFACE}

This study did not find its genesis in the tropical climes of South Florida but rather in the cooler regions in Monterey County, California. It was there I was exposed to the grotesque ugliness that comes from perceptions of otherness. During bus rides to and from high school in the mid 2000's, I often had to watch people shake their picket signs at the direction of the bus, telling the students that English is the only language welcome in the U.S., Spanish should not be spoken, and "illegals" should get out of the country. It was bizarre, as it goes without saying that other languages spoken in the area-notably Korean, Italian, and Japanese — had never been harangued in such a fashion and most of the people in the area are Spanish speakers. Though those languages and others would be unfortunate candidates for this type of aggression in other cities in California, the reality is that according to the 2010 census, Salinas is $75 \%$ Hispanic. The corner they picked was also across the street from the beginnings of the farming fields where the majority of the workers were Mexican migrant workers. The juxtaposition between the farms and migrant workers with the xenophobic picket signs seemed purposeful.

The negativity I saw did not leave once I graduated from high school but rather morphed into a sideshow spectacle where the real boundary between perception and reality was language. At a hamburger restaurant in Monterey where I worked, the cooks and the rest of the back of the house were treated like animals at a zoo: they were there only for our amusement and comfort. They were constantly talked down to, disrespected, and treated like demi-humans, mostly on the basis of language. During the training of a 
new manager at the restaurant, the cooks had to teach him every position in the back of house. On the day he had to work on the line, he constantly yelled out obscenities in Spanish and called the cooks "frijoleros" ("beaners") for his and the English speaking staff's amusement. When the cooks were given directions in English, it was forceful and had a militaristic tone; when they were addressed by those who spoke either a little Spanish or knew a few words, it was infantilized and condescending. Bridging the gaps that existed linguistically is not easy, but this scene was the same almost everywhere in the county. Busboys who only spoke Spanish faced similar alienation, but those who were bilingual were given passes into the "normal" world of the monolingual English speakers. The cooks themselves were all articulate and educated people (the head night cook had a degree in Chemistry but made more money flipping burgers in California) but were not so in the "normal" language. This inaccuracy and treating people who are learning another language as a spectacle lit a fire in me that burns to this day.

I had also felt the spectacle first hand when I began to study foreign languages for the first time in high school and college. In high school, I selected Japanese to study for two years and began to observe that the students who struggled the most with developing communication skills in the language were the ones who were uncomfortable with speaking in class at all to begin with. In college Spanish classes, it was more of the same but also people who did not seem to take the class as seriously as they should have that struggled the most.

With the cooks at the restaurant I worked at, I noticed it was the same for them. The difference and the problem was that they did not receive the same courtesy from the 
employees and managers as my classmates would receive from the teachers and students. Instead, it became a joke and a game for the employees as the cooks tried their best to speak some English. It was infuriating, because I knew that when they were sitting in a foreign language class they very likely did not have to deal with the same levels of disrespect.

In order to fix this problem and to expand my own purview, I took the opportunity to move to Miami with my grandmother. My goal was to master Spanish in a more linguistically open environment and to experience first hand what it could be like to live in a place where bilingualism was the norm and not spectacular. This would be the best way to eventually make broader changes so people would not have to feel the same way my former coworkers and I would feel.

Upon relocating to Miami in the summer of 2009, I quickly realized that I would never see Spanish speaking people being treated like zoo exhibits for as long as I stayed here. Unfortunately, I also quickly realized that the Haitian community of Miami is fighting some of those same issues I saw in California, albeit to a far lesser degree. Although the people in California were somewhat willfully ignorant and had chances to take Spanish language classes (many of them had even taken classes), that is not the case for Haitian Creole in Miami. The 2010 earthquake struck Haiti during my time at the University of Miami, and almost as a knee-jerk reaction the Haitian Creole language classes were expanded. My instructor, Cherol Marcelin, was a teacher with great innate pedagogical skills who imparted deep understanding of the language and culture to his pupils, and I am glad to have learned from such a pleasant person. 
After graduating, I began to work in restaurants again in order to make enough money to live on while I began to explore more serious post-baccalaureate options. I worked with several Haitians and quickly realized that in order to become more proficient in the language, more classes would have to be taken and more time would have to be dedicated to conversations with native speakers. I also realized that even my (at the time) rudimentary grasp of the language was more than that of many other people; I felt like my speaking ability could be an asset for Haitian students and began my teaching career in Miami-Dade County Public Schools.

There were several trigger moments that took my interest in literacy instruction and problems faced by Haitian students in Miami that occurred early on in my career. One of the most memorable ones happened when I was working as a "literacy interventionist"- a part-time position that helps teachers during lessons and works with designated groups for thirty minutes a day. The very name of the position was my first indication of the deficit model mentality adopted by district leaders in terms of how to assist students who just need some extra help for a wide variety of reasons. Instead of telling students that I was their "interventionist," I used the more neutral term "part-time teacher" to let them know that my function was to help them progress and nothing else. The teacher was a monolingual English speaker and would receive help from an ESOL teacher during one of their ESOL heavy classes, mostly due to the size of the class roster (there were not enough desks to accommodate each student and a few would have to stand until some of the students were pulled to work one on one with the ESOL teacher). The ESOL teacher would show up after the lesson and take a group of the students to 
another classroom for intensive instruction for the rest of the period. The ESOL teacher was a native Spanish speaker from the Caribbean and would spend much of the time chit-chatting with the students in Spanish instead of practicing their writing skills in English. This would sometimes even last for the whole session and effectively box out the Haitian students from the banter and camaraderie as well as quality instruction. After the teacher returned the group of students to the regular teacher's class, they had a brief exchange that ended in chuckles. The teacher later told me that it was because they both agreed that the Haitian students are not doing their work because they "don't understand and are just dumber." It was deflating, as a lot of my time with those same students was spent trying to help them bridge the gap between Haitian Creole and English, using the small fraction of the language I had learned and retained from my time at the University of Miami, not giving up and labeling them as "dumb."

There are other stark instances when I realized that Haitian students needed more control over their education and more understanding from their teachers, but most of my other memories are a smattering of the ignorant comments I have overheard about the language and culture, i.e. they eat cats, it is a "broken language," there is only poverty in Haiti, they smell bad, and so on. After traveling through Haiti and seeing the ingenuity of its people and their linguistic talents (many people became conversational in languages by listening to tourists), I came back to the 2015-2016 school year equipped with much more information to dispel rumors than I had in years past.

My experiences at the TESOL International Conference and the Conference on College Composition and Communication (CCCC) also provided experiences that this 
project was conceived from. As a young teacher, I had been struggling with trying to figure out how to get my students to really use the copious amounts of feedback I had been giving them, both for topical things like grammar and spelling but also for deeper meanings like the implications of their ideas. My suspicion is that much like the cooks from the restaurant in Monterey felt uncomfortable from the humiliation when they tried to speak English or the way Spanish was demeaned by the rest of the staff, the students were interpreting the feedback in similar ways or possibly even felt similar humiliation from the teacher's suggestions. At the CCCC, I learned about AES software for the first time from a program called Pearson Writer. The program was a writing assessor, research tool (similar to Google Scholar), and spell check rolled into one piece of software. Though the program would have cost too much and the rest of the school year too short to implement this type of program into my curriculum, I was immediately seized by its possibilities as something to help ELLs and students that struggle with reading and writing. If the students were managing their writing projects while using the software to make revisions and edits, there could be a chance that the awkward feelings of writing feedback that are analogous to Krashen's affective filter theory (1982) could be mitigated. Instead of reviewing the teacher feedback and worrying about their grade, their independence could potentially allow them to make more wide-scale revisions and improvements without stressing out as much from issues like teacher perception. There exists, however, significant pushback from a variety of professionals from using this type of technology at all. 
This thesis project will begin to investigate whether these software programs can be used as revision tools for students - namely the level 3 and 4 ESOL students in my school — in the middle of the writing process. The high level ESOL students are in a unique position because they speak English but still have nagging issues (spelling, fluency, pronunciation, and test-taking skills) that are holding them back from leaving the ESOL curriculum and placing them in mainstream classes. With writing, this can become tricky because their English is strong enough to compose essays and papers but still greatly benefit from intensive revision instruction. They might also feel discouraged if they were to be considered "dumb" for being ESOL students and were given oversimplified writing assignments. AES could help bridge the gap between where their skills are and where they need to be without drastically changing the curriculum and giving them more control over their writing. If they are amenable to the inclusion of the technology to help them revise, it can potentially increase their skills and self-efficacy in writing.

\section{Piloting the Program}

Before conducting the study, I piloted use of the paperrater.com AES program to see if it would work for my students. I did this by submitting my own work through the program and asked former students to test it out by doing the same. While experimenting with the program, I took reflective fieldnotes (Bogdan and Knopp Biklen 2007) in order to keep track of my own "speculation, feelings, hunches, and prejudices" (Bogdan and Knopp Biklen 2007, 122). I noted that while the paperrater.com format makes sense for 
college students and online personas such as bloggers, journalists, columnists, and social media personalities, for Florida high school students the system is somewhat counterintuitive because by performing the tasks required from the rubric, their "originality score" could go down. To avoid this problem, I planned to explain to the students that a lower score was not always a bad thing as it meant they included concrete, specific textual evidence into their essays. Furthermore, I also planned to encourage them to take more time on their writing as well as extend the length of their papers. This fundamental approach also created more pathways for constructive dialogue between myself and the students by allowing us to engage more in further developing their ideas instead of forcing them to mimic someone else's during the project.

With respect to grading and assessment, teachers might grade other students via comparison models with work from other students' the problem with the software also adopting that model is that it could potentially dock points for truly outstanding originality and creativity, outstanding enough to buck the trend of what other students wrote for their "perfect" essays. This is especially the case for ESOL students, as their linguistic and cultural experiences might not be conducive for the production of their very own mimeographed "perfect" essay. Paperrater.com, on the other hand, opts to focus more on structural features of writing rather than attempting to figure out what their algorithms feel is a "perfect" essay. 


\section{CHAPTER I}

\section{INTRODUCTION}

This chapter outlines the entire project, the conceptual framework, and the research questions by providing synopses of the major aspects of this thesis.

\section{Haitian Immigrant Students}

Haitian and Haitian-American students face unique challenges in the U.S. education system. In South Florida, a region in the U.S. with over 300,000 people of Haitian descent (per the 2010 census), Haitian youth often contend with teachers who do not understand their language or culture, peers having difficulty categorizing with familiar mental checklists, and different cultural norms in regard to the relationships between schools and families/communities (Degraff 2005; Degraff 2010; Walsh 1999). Along the Biscayne Corridor (which includes Little Haiti and the surrounding neighborhoods) and North Miami, Haitian youth also have to deal with powerful criminal forces in their neighborhoods, notably gangs (including the Zoe Pound) as well as impending gentrification starting in Little Haiti (Chang 2015). These neighborhoods are outlined in the maps in figure 1 below. 
Fig. 1. Maps Outlining North Miami, Little Haiti, and the Biscayne Corridor (Major

Haitian communities of Miami-Dade County)
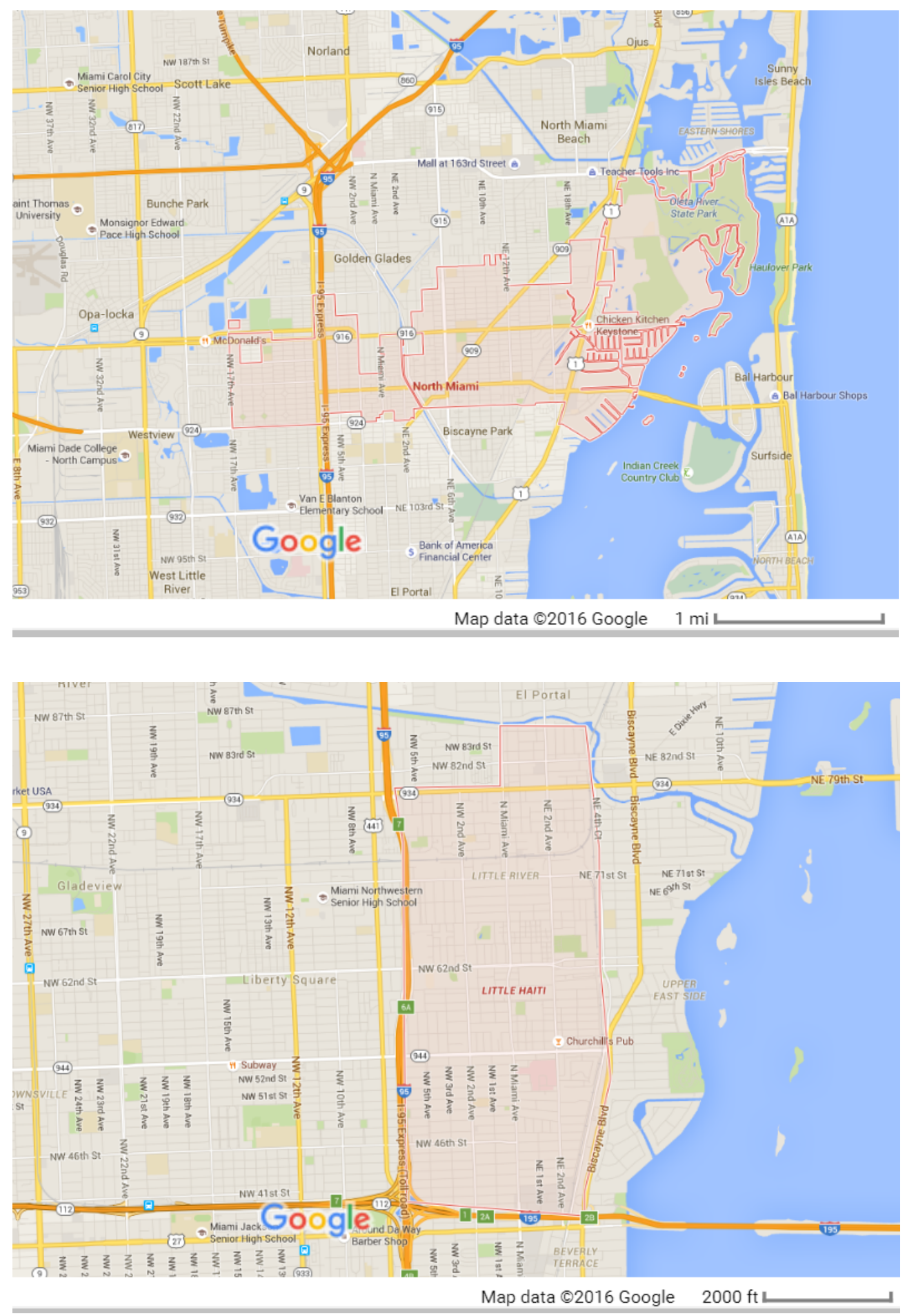
The acculturation process for Haitian immigrant students is also atypical as they tend to adopt African-American culture instead of a mainstream U.S. culture; this should not be a big issue, but misunderstandings, especially linguistic ones (Bean et al 2011) often arise between them and their oftentimes non-black teachers. When Haitian immigrant students arrive to U.S. schools, they are constantly harangued by teachers due to their differences, simultaneously being told they do not fit in while being told that the only way to read the text is the way the test wants them to read it (Aukerman 2013, 56). Haitians have a rich linguistic history that could be used as a foundational source for their English Language Arts (ELA) education, but that source is boxed out in favor of the "right" answer. Spanish speaking students, both native and immigrant, tend to face the same problems at schools where there are many Haitian and African-American students and try to assimilate with them to mesh with the student body, create micro-cliques among themselves and observe distantly, or combine a little of each (Vanderkooy 2011, as well as my own observations). This creates a tension because many of their teachers do not understand Hispanic cultures and understand even less about the issues regarding assimilation and how to walk the tightrope of being the "other" in a student body of "others" (Roca 2013). This dissonance can also be seen as a clash with the primary discourses that are "not by overt instruction, but by being a member of a primary socializing group (family, clan, peer group)" (Gee 1989). It is not impossible for teachers unfamiliar with the primary discourses of students to be effective educators, but it can be an obstacle if the teacher does not meet the students where they are at. 


\section{Linguistic Bases for ESOL Students in Miami}

Of the close to $80 \%$ of people in Miami who speak another language other than English at home, the majority speak Spanish (2010 census). Though this could make for interesting discussions about the differences of ESOL students in Miami vs other parts of the U.S., it also creates a strain between the many Hispanic ESOL teachers (reflecting the census numbers) and their Haitian Creole speaking students. Sometimes, the fundamental differences between student and teacher can create conflict, and though teachers who do not feel comfortable might not tell their students what they think about them to their face, their attitudes would still permeate into their pedagogy and be detected by the students (Rist 1970). They might then carry it in themselves as their very own scarlet letter despite the teachers' opinions being fundamentally problematic.

Another issue is the consistently held belief by students and teachers in Miami (not just those affiliated with ESOL) that Haitian Creole is something akin to a "broken French", "basically French", "the slang version of French", or something spawned from a people who “didn’t understand French" (Lefebvre 1986, 2006; Degraff 2005). These barbs put it in the collective psyche of the student body and faculty that the L1 of Haitian students is essentially flawed and is the product of people who were "too dumb" to learn French, totally disregarding the complex history of the language and the linguistic segregation imposed by the French onto the slaves of Saint-Domingue (Haiti) (Lefebvre 1986; Degraff 2010; Zéphir 2015). 
In order to give Haitian students at my school a stronger voice amongst the students I come into contact with everyday (not just ESOL students), I spent this past summer taking intensive Haitian Creole classes with Nicolas Andrè and traveling throughout southern Haiti for two weeks as part of the Haitian Summer Institute (a FLAS Fellowship program). This helped me contextualize the difficulties and strengths Haitian students bring with them to the United States, even if they are transmitted to them from their parents. Haitian Creole can be a source of strength for Haitian students (Bean et al 2011), as the majority of the words do indeed come from French; this could help students with higher level vocabulary terms that come from Latin.

\section{Writing Issues for These Students}

Haitian Creole is not a commonly spoken or studied language, and the educational system in Haiti is usually in flux as a consequence of the history of political turmoil in the country, especially at the middle school level and above (Degraff 2010). When Haitian students come to the United States for school, they bring those issues with them, and teachers here are still learning about Haitian culture and how to help them make the transition into American schooling and life. For example, according to a study on the Haitian Literacy Program at Hyde Park High School in Boston, researchers discovered that the key elements creating success in the program since its founding in 1988 have been "(1) the commitment and dedication of the native language teacher; (2) the relationship between English as a second language and native language teachers and 
instruction; (3) the interdisciplinary, thematic, and self-contained instructional format; and (4) the self-determination of the students" (Walsh 1999, 1). In Miami, many ESOL teachers are Hispanic (reflecting the 2010 census) and make disparaging comments about their Haitian students (I have overheard negative comments by teachers at four different high schools); they also can cover up any potential deficiencies in their own English because of their ability to scaffold complicated ideas in Spanish to their students, a luxury rarely enjoyed by Haitian students in contrast to the situations many Spanish speaking students enjoy. This is an issue I observed during my time as an interventionist with the Spanish speaking ESOL instructor and his rapport with his Spanish speaking students. The success of the Haitian Literacy Program at Hyde Park (Walsh 1999) is indicative of the deficiencies in Miami, as the failures here have their equal antipode of success up there.

Though this project also includes a number of Spanish speaking students, much of the inspiration of the initial idea came from the need to find an activity to improve the quality of the education of Haitian students and to give them more metaphorical breathing room (Krashen's Affective Filter 1982). I also felt the need to take it upon myself to devise a new method of essay revising that they could directly benefit from in order to best apply the knowledge I gained through my participation in the Haitian Summer Institute at FIU. 


\section{Definition of "Right"}

Due to the unrelenting implementation of standardized testing and their implications for both students and teachers alike, language arts education is beginning to sterilize in favor of what researcher Maren Aukerman (2013) describes as "rightness" in reading comprehension: "The perceived imperative to guide students ever more narrowly toward standard interpretations and predetermined strategies increasingly dominates reading classrooms as teachers face mounting accountability pressures from policies such as the No Child Left Behind Act...standardized reading tests where, after all, there is only one designated 'right' answer" (57). Limiting a student's interpretation of a text to one of four bubbles on a test has ramifications for writing as well, as groups of people are attempting to pare down the presentation of written ideas and explanation to a more standardized form as well through AES software. A variety of studies (for example, Shermis and Hamner 2012) have shown that AES software can be just as effective and are almost indiscernible as a human grader, whereas others (including Perelman and his collaborators at MIT as reported by Kolowich 2014) have shown that students at all levels can game the system by writing with grandiose vocabulary and minimal grammar mistakes.

\section{Self-Efficacy and Agency in the Writing of High School Students}

There is existing research on the issues of motivation and other emotional facets for high school students in general, but it is an even more critical aspect of second language acquisition (Krashen 1982; Gee 1989 Corcoran 2009; Ghazvini \& Khajehpour 
2011). Students in a recent report by María Luisa Carrió-Pastor (2014) found that two groups of students responded to their English language educational experiences differently: one group was taught through repetition and presented the task as if it could only be performed in one way; the second group were allowed to "plan individually their own learning, and decide what to do to or emphasize in each lesson. The first group who had the repetitive and narrow lessons reported that $75 \%$ of them did not feel confident in their English skills in the class. The second group who had more autonomy reported that $75 \%$ of them felt confident in their English skills and $90 \%$ of them felt that their English improved.

I hoped that this project could replicate some of those results by allowing the students not only to determine which parts of the feedback they agree and disagree with from the AES software (giving the writing process more of an open-ended feel like that in the aforementioned second group) but also to allow them to write the early notes and first draft in their native languages (with the provision that they understand the extra work required for the translation process). A report edited by Bean (2011) was referenced to develop a framework for the application of the idea of including more first language use into the classroom. The students will never be prodded to use their home languages, but I believe by having the option and being in an environment that could help "develop literacy in the mother tongue" (Cummins 2001), the students might respond positively to the software and the writing process in general. Pressuring the students to use their home language would potentially skew the results of the project and also create a tension 
similar to that which comes from teachers who pressure them to never use their home language.

Despite Miami's status as one of the most bilingual and multicultural cities on the planet (2010 census reported 59\% of Miami residents being born outside the U.S. and close to $80 \%$ of residents speaking at least two languages), teachers and the school district do not take advantage of the linguistic resources available from the communities they serve. Some teachers at my school, especially Teach for America corps members, even ridicule their students for their varied backgrounds and fail to cover the basics, such as pronouncing their names even half-right. This tension also manifests itself through the district pacing guides (now called "Supplemental Instructional Guides"), which would actually be a great tool for school districts other than Miami-Dade. There are no texts or ideas suggested that reflect reality for students in Miami (for example, the "Hispanic" texts are almost always from Mexican-American authors and the "multicultural" texts include a decent array of documents written by Asian-Americans). There is also a narrow minded focus on getting everything done in a specific type of way robbing the students of their creativity and ability to breathe in their own classes. By letting the students use the feedback as a tool for their own work rather than tying it down to a grade that reflects the narrow views birthed by high-stakes testing, I hope that they will be able take more actual ownership of their education instead of getting the "right" answer. 


\section{Current and Future Use of Automated Essay Scoring Software}

Automated Essay Scoring (AES) software is a software developed by programmers and developers to assign a grade to student writing, sometimes based on algorithms from aggregated information of teacher grading and feedback patterns. For example, a program from ETS uses the information from human graders assigning scores to 500 essays on a certain subject to create the pattern of grading that the software imitates. Some states and school districts see AES software as "a viable, economically feasible alternative to the expensive endeavor of wide-scale assessments" (Warschauer 2006), and others feel it can assist with the reality that "class sizes continue to grow and instructors are expected to provide more rigorous evaluations than multiple choice tests" (6).

There is a faction of professionals, including Noam Chomsky, who look askance at AES software and have even created an online petition called HumanReaders.org (Paulus 1999; HumanReaders 2013) to fight against them, particularly when used as an assessment tool for high-stakes testing. The purpose of this project is to find the middle ground by investigating the possible usefulness of the more private nature of the feedback given by the software as opposed to using it as the final assessor; if the software can be analogous to the calculator in the math classroom (checking the steps along the way and not necessarily finding the solution), then it should be used more often. The effects of teacher and peer feedback on student writing is mixed and has been determined to be mostly positive or negative (Paulus 1999). There are some findings, however, that have 
shown that when students make the revisions on their own they tend to do more surface level editing than the meaning level changes elicited by peer and teacher feedback (Paulus 1999; supported by Hult 2008); this project sought to discover if that holds true for the feedback given by a machine.

I attended the 2015 Conference on College Composition and Communication (CCCC) in Tampa and gained in-depth knowledge of the variety of AES software. Most of the presentations and vendors spoke about the accuracy of the programs as a final assessor and the possibility that they would be sensitive enough to give feedback to ELLs that reflected their L1 grammar tendencies. Unfortunately, there were few attendees who were interested in the utility of the programs for high school students. It was there that I was inspired to research the subject and devised the first ideas of letting my own students use them to improve their writing scored by the Florida Writing Rubric.

Academics like Les Perelman (reported by Kolowich, 2014) at MIT have demonstrated time and time again that many of the different programs are easily gamed by creating the Basic Automatic B.S. Essay Language (BABEL) Generator, a program designed to game the software into giving high marks. Currently, AES software is being used as a tool to replace human graders for essay scoring. This research project was to reconfigure the current use of AES from a final assessor to a tool for students at all levels to use in the middle of the writing process. 


\section{Conceptual Framework and Research Questions}

A three-pronged approach to this entire project guides the research: 1) the current and future use of AES software and other technologies pertaining to literacy, 2) self-efficacy and increased agency in writing for high school students, and 3) issues of linguistic bases for high level ESOL students in Miami, particularly for Haitian Creole speakers. The inspiration, design, research, and overall conception of the current project was the result of a three experiences that became the three-pronged set of ideas that are guiding this project: the 2015 TESOL International Conference and 2015 Conference on College Composition and Communication, the low expectations and its subsequent outcomes of ELA teachers in Miami, and issues for Haitian Creole in the U.S. and Haiti.

These experiences helped formulate the following two research questions for this project:

1. When using AES software as a tool in the writing process, do high level ELL students report an increase in their sense of self-efficacy as a result of revising of their work?

2. Do high level ELL students report, as a result of writing essay outlines/notes in their home language (especially Haitian Creole), an increase in their feelings of confidence when writing their final drafts in standard English? 


\section{Purpose of the Study}

The purpose of this study was to evaluate the effectiveness of AES software in improving high school essay writing (especially in standardized writing tests and Common Core aligned writing rubrics) and self-efficacy among high level ESOL students. Special attention was paid to the linguistic bases of the students involved, especially Haitian Creole, and the possible effects of letting students use their home languages as part of the writing process. The goals and purpose of this study have a three-pronged focus that were touched upon throughout this document:

In high level ESOL students, is there a difference between the software used as a final assessor and the software used as a tool in the middle of the writing process in

1. Improvement in standardized test scores based on Common Core aligned writing rubrics,

2. Perceived self-efficacy and autonomy in writing, and

3. Allowing students to use their home languages in the writing process? As more educational agencies across the country look to AES software to replace their human graders, more people and researchers are growing concerned that there has not been enough research done on the reliability and validity of the software.

Despite the visceral reactions this topic evokes, both sides of the argument over whether or not to use this software agree that in one way or another AES software can help teachers and professors grade papers more efficiently and will undoubtedly become

more ubiquitous in writing assessment in the near future. Outside of the philosophical and 
practical arguments ignited by these issues, the fact remains that the software is already sophisticated enough to give valuable feedback on student writing, such as vocabulary suggestions, organization tips, and other cosmetic features of writing. Whether or not it will ever reach the point of truly understanding human subjectivity in writing and to detect real meani distracts people from the very practical use this technology has for students: to be a spell check on steroids. This study investigated if AES software can be used not as a final assessor controlled by a teacher, but instead as a source of feedback controlled by the students to make measurable improvements based on the Florida state writing rubric.

The students who struggle the most with the imposed "rightness," inflexibility of language, reading, and writing from their teachers are the students who have the most to overcome, especially English language learners. Other groups of students, such as other minority groups, dialectal speakers of English (e.g., African-American Vernacular English, Appalachian English, Caribbean English, and others), and students with other characteristics that create problems in their education also contend with the same forces, though not quite to the extent as ELLs. In Miami, Haitian students have a unique dissonance as they speak a language other than English (like the majority of the population according to the 2010 census), deal with the issues other black students deal with (teacher perceptions and expectations, more frequent punishment, teachers questioning their intelligence, etc.), and face unique issues as a result of their immigrant status (especially coming from what is often referred to as the "poorest country in the Western Hemisphere" on a per capita basis). 


\section{Significance of the Study}

The problem of "rightness" faced by ESOL students — especially Haitians — runs counterintuitive to the creative and private space the mind needs in order to expand its linguistic capabilities and understanding. When the "right" answer constricts human language to one bubble out of four or five, students become anxious because might not come from a home or country where their interpretations of a text or poem coalesce with the "right" definition demanded by the state. As writing goes through a similar transformation, there is a great need for students to have more agency and control over their writing and for them to go from being producers of writing to directors of their own ideas. By allowing students to submit their work to an AES program before handing it to the teacher, they will be given a potentially valuable opportunity to review what would be (according to proponents of the software) the same marks and notes that a teacher would give them anyway. But, instead of seeing those notes and worrying about them being tied to a grade, they will have free reign over them, and could be able to determine which kinds of feedback might bring to light the only "rightness" which should have ever mattered in the first place: their own.

Students from these communities in Miami and analogous ones across the U.S. often feel discriminated against and have to fight tooth and nail for their voices to be heard and respected (Chang 2015). In my own experiences, some teachers have told my classes or other students that no other language but English should be spoken at school, severing the language the majority of my classmates would speak at home from their 
education. In Haiti, Degraff (2005) reported that one of his teachers had "NO CREOLE" as the second most important rule listed on a big poster, behind only "NO GUNS." The dissonance between the students' languages, classroom and school policies, and the stress of the teachers in the U.S. has muddied the focus of education itself. Despite the paranoia, though, educators are not being informed of the literature and research, though for some it may be because of their perception that the research does not apply them but to other educators (Cochran-Smith \& Lytle 1990). Letting students use AES software and making that the normative function of the software can help them navigate through the mess they are confronted with by letting the art of writing be a more private and intimate activity, one that gives them the breathing room they need to develop as creative thinkers and writers. If AES were to increase its presence in K-12 settings in the United States, the role of literacy coaches and teachers would likely not be diminished (to the chagrin of some software developers) because they will be the ones to help explain any aspect of the feedback that might be confusing or to give language to why the student might have made the decisions they made in terms of writing and incorporating feedback. This could be akin to a calculator being used in a math class: there will always be a need for the math teacher to take students through the steps of a formula. Though more research would be needed to determine widespread efficacy and benefits of this idea-by stripping the technology of its power and reassigning it as part of the writing process instead of the endpoint of it (when the final product is submitted for grading and evaluation), teachers and students alike would be able to reach their goals: 1) students developing as writers on their own terms and 2) teachers helping more students pass high-stakes tests. 


\section{Definition of Key Terms}

Automated Essay Scoring software can be defined as software programs which assign grades to essays written by humans in educational contexts, such as in class assignments, in class or school wide exams (exams written for the same class offering by different professors at a university), and standardized tests (GMAT, GRE, state tests, etc.). The topical features of writing are referring to the lexical and grammatical components of writing rather than the meaning of the words. For example, the topical features of the famous poem "The Road Not Taken" by Robert Frost would not include the deeper meaning of what it means to take or not take the beaten path, but rather would be the words and grammar which comprise the poem.

Rightness refers to the idea in literacy and reading education where teachers are coaching students to come up with the right answer in order to perform better on standardized tests rather than allow them to come to their own conclusions.

\section{Synopsis}

This project ties together three issues which impact students from all over South Florida, but especially in Miami: ESOL education, linguistic bases in ELA classes, and technology in the classroom. As the Miami-Dade County Public School District moves to include technology at all levels of K-12 education, teachers and staff need to familiarize themselves with new hardware and software. Understanding AES software is an integral part of this process as Florida could very well make the move to use them as the primary grading mechanism for statewide assessments. This project also aims to devise a method 
to which students and teachers are not subject to the technology but rather use these new programs as one step in the middle of the process, treating the technology with its original purpose: as a tool. 


\section{CHAPTER II}

\section{LITERATURE REVIEW}

\section{Introduction and Basic Issues for ELLs}

Writing and the acquisition of the requisite skills, lexicon, and grammars of formal academic composition are notoriously difficult for ELLs to develop. Understanding the cadence and rhythm of the language in the written form is a difficult proposition for learners, not to mention the trickiness of operating in its different registers. Mastering these skills calls for patience from their teachers with respect to open-mindedness regarding the interrelatedness of multicultural contexts (Ovando and Collier, 1998). Furthermore, it also requires access to teachers and resources that are given to students by chance or by paying the right price for services (such as private tutoring, private group lessons, and travel). The right price in this sense is both literal and figurative: students with a higher socioeconomic standing can afford for both tutors and for strong education opportunities; wealthy students who are forced to relocate from their home country can afford to have a different mentality at school than someone stripped of their resources and garner "refugee" designation; students who come from the 'right family' and the 'right background' (not to mention the 'right' gender association) are known to not have to deal with the deleterious effects of bias (and other phenomena) at the same rate as students who do not have the 'right background' (Dwyer and McCloskey 2013). Indeed, one of the fundamental aspects of reading comprehension is background knowledge. Though background knowledge is available to people by virtue of our shared 
humanity, much is not as immediately available, and the issue becomes murkier when background knowledge in the L1 is factored in. Not all students in the Dwyer \& McCloskey study emigrating from their home country had a steady education, and some had close to none. If this type of student is exposed to a story that includes an element which requires background knowledge that they have no history with, they are immediately excluded from the story in a sense: if a student has never heard of Japan, a story referencing sushi is more likely to serve as a source of consternation than education.

Compounding the issue is the broad net the term ELL casts in the U.S., as students' specific backgrounds are not considered and categorized: "beyond the labeling of ELL, these additional descriptions of students are not teased out in state-reported data. As a result, in the U.S. and indeed worldwide, little is known with direct respect to literacy development of refugee students" (Dwyer and McCloskey 2013, 88). Other research, though, indicates that some level of anonymity is for the best, as teachers displayed bias and prejudice towards the writing of ELLs based on their nationality and name (Rubin and Williams-James 2011, Land and Whiteley 2012).

There is, however, substantial research and experimentation on ways to alleviate those issues through traditional pedagogical scenarios through peer tutoring, writing centers, and critical pedagogical application (e.g., Rafoth 2011, Palacio 2011, Mulqueen 2011, Severino 2011). Another method being applied in classrooms to break down the barriers preventing the success of ELLs is technology. Writing and writing evaluation software is more than a burgeoning market: some states utilize them for official grading, promotion/demotion, and other factors for teachers and students alike. Though this thesis 
will in no way advocate the use of those technologies as the chief evaluator of high-stakes testing, it is important to recognize this growing trend. This project, however, explored the capability technology has to increase ELL writing and literacy success in the L2 by ameliorating the affective filter suggested by Krashen (1982).

This chapter delineates the three aspects of the conceptual framework which have guided this project: Current and future use of AES software and other technologies pertaining to literacy; self-efficacy and increased agency in writing for high school students; and issues of confidence and linguistic bases for ESOL students, particularly for Haitian Creole speakers. In fact, to the degree that cultural and linguistic background information are vital to the development of this study, an in-depth examination of Haitian Creole language is included in this review.

\section{Current and Future Use of AES and}

\section{Other Technologies Pertaining to Literacy}

In order to understand the role technology (primarily computers and word processing software) could play and currently plays in literacy instruction for ELLs, the current research regarding writing oriented software in general must be addressed.

Computer and technology has become ubiquitous in modern society, and choosing not to acknowledge that as a teacher is to preclude students from learning and experimenting with technology in a controlled environment. According to Stine (2008), "In a remarkably short time, the computer has evolved from being a tool with the potential to improve student writing to being the tool with which people write." (389). As important 
as it is to introduce students to technology, recent developments in literacy education software have become important to understand. There has been contention among academics, such as a back-and-forth debate between Mark Shermis and Les Perelman (Kolowich 2014; Perelman 2013) about the role of a specific type of software: automated essay scoring.

Word processing software in general is treated much the same way as a typewriter and basic proofreader in the sense that it is seen as a tool. Automated essay scoring software, however, is in the beginnings of transforming the way essays are judged at the national level. According to Shermis (2014), the software is an algorithm based program which 'reads' essays per their specific formula and give it a grade. The algorithms themselves are derived from research and, popularly, data extrapolated from human graders on a large scale. Software designers are given thousands of essays that have been graded by humans and subsequently create the algorithm based on the grading patterns of those essays. The appeal of this for state education departments is that, in theory, "machine scoring algorithms...make it possible to score [large] volumes in a timely and cost-effective manner" (Shermis 2014, 54). Shermis gives a practical example with the state of Florida: there are "approximately 180,000 students in each grade level" (20), and if "each student...had five essays graded, the state would be required to evaluate almost 11 million documents per year" (20). Though this example fails in the sense that the state would probably not grade five essays per student in even one grade level, it introduces the underlying idea that this technology might make it easier for states to encourage and monitor more writing from its students. Without the need for human graders, the state 
could grade the hypothetical 11 million documents and create a new norm for writing.

Common Core, and its focus on "college readiness rather than a mastery of basic high

school skills" (20) make a higher quantity of writing imperative, an imperative that

automated essay scoring (AES) could resolve.

Blood (2011) offered a set of positive and negative aspects regarding the use of

AES software. A synopsis of Blood's aspects is presented in figure 2.

Fig. 2. Positive and Negative Aspects of AES Software (Blood 2011)

\section{Several Positive and Negative Aspects of AES Software}

Positives Negatives

- Increases speed and efficiency of grading for wide scale assessments (GRE, TOEFL, GMAT, etc.)

- Proven accuracy and correlation across multiple programs to human graders

- Eliminates bias in writing assessment as they can only evaluate the writing, not the writer

- "The matter of whether or not automatic essay scoring tools apply scoring rules accurately and consistently has not been a matter of debate as internal consistency is an inherent trait of such systems." (Blood 2011)
- Wide variety of programs make it difficult for educators to determine which one best fits their needs

- Programs are not impervious to error and might be deferred to by human graders anyway

- Favors students who have consistent access to computers and are used to typing (especially in timed writing)

- "If the scoring tool in question is trained on surface features of candidate responses in order to predict the average holistic-scale rating of human raters with high reliability, we are likely to conclude that it is less appropriate for testing situations in which substantive feedback is highly valued." (Blood 2011) 
On the flip side, there is some concern due to the ability to 'game' AES in the sense that, as of this writing, the software cannot assess coherence in writing and instead relies on grammar and lexical patterns in writing. For example, Perelman (as discussed in Kolowich 2014), an outspoken critic of AES, with his MIT students created a program whose sole function is to create random, non-coherent sentences that would receive high marks from AES: For example, one sentence from a instantly generated essay was "Privateness has not been and undoubtedly never will be lauded, precarious, and decent" (Kolowich 2014, A12). Perelman's program wrote this “essay in less than one second, using the Basic Automatic B.S. Essay Language Generator, or BABEL, a new piece of weaponry in his continuing war on automated essay-grading software." (Kolowich 2014, A12). This "privateness" essay was then fed into MY Access!, an AES which utilizes the same software that the GMAT uses as a second reader, and received a 5.4 out of 6 "with 'advanced' ratings for 'focus and meaning' and 'language use and style'” (Kolowich 2014, A12).

Though the BABEL program is more philosophically driven than practical, it still highlights the issue of the limits this technology currently has. During the research for this paper, there were several instances where researchers reported that AES would inexplicably give a poor paper a high grade or vice versa, leaving the teachers and programmers puzzled over such anomalies. However, even according to Perelman (2013) himself, as well as his colleagues at MIT, this technology is on the horizon and is already being used with few problems in classrooms across the U.S. (at times in conjunction with a human grader to prevent glitching). This paper discusses the potential they have not to 
'replace' the teacher in a sense but rather their potential to shake up the traditional notion of the writing process and to, most importantly, serve as, in the words of Soper (2013), a "spell check on steroids."

\section{Conjunctive Problems for ELLs and AES Software}

Technology and literacy instruction for ELLs is a field which must find its application inside classrooms intertwined. Though much of the information gleaned from the sources were designed specifically for university level ELLs, high school aged students are, generally, close enough in age to university students that the theories and practices will still have plenty of use. The most important difference, however, is the more pressing need for comfortability for high school students. Comfortability can include things like the affective filter (Krashen 1982), peer editing and reviewing (Ebersviller 2013), text rich environments that help classrooms feel more welcoming (Corcoran 2009), deeper interpersonal engagement between teachers and students, and teacher sensitivity (Rubin and Williams-James 2011). The deeper engagement needed for high school ELLs is for teachers, schools, and other educational entities to understand the unique backgrounds of each individual student, how their background affects them personally, and the experiences that culminated in their presence in an ESOL classroom (or other L2 settings).

Teacher sensitivity is a major factor in all of education, but it is acutely pervasive in literacy instruction. Rubin and Williams-James (2011) conducted an experiment that measured the statistics of this phenomenon and came to the conclusion that even the same 
essay will be graded lower for students of certain backgrounds. In their experiment, university writing instructors were given six different essays which contained the same number of errors; each of the errors was also of the same type: "word order reversals, wrong tense, wrong preposition, lack of pronoun/antecedent agreement, minor spelling errors-mainly homonym confusions, and omitted articles" (361). They then created three fake student profiles that represented backgrounds which "are unlikely to engender non-generalizable nation-specific stereotypes" (361): "Rutai Chaichongrak" from Thailand, "Erik Grundtrigian" from Denmark, and "Ray Wilkinson" from Texas. Even when given the same exact essays but switching the names, the instructors graded the Thai student more harshly than the other two students at around twice the rate. At the high school setting in the U.S., where competition among students is the norm and comparing grades is also normative behavior, this trend could prove ruinous to the psyche of the students, especially ELLs. This issue is also magnified when considering the focus on the group effort for certain minority student groups versus the emphasis on the individual for mainstream America (Bean et al 2011). AES could help both teachers and students evade this issue by allowing an unbiased computer assess, a potential huge plus, whether or not the essay followed the patterns of writing expected from the teacher and the writing rubric (assuming that teachers would be welcoming of such a proposition). It can also help by allowing the student and the teacher to engage the students' written work via neutral third party (AES) instead of the traditional hierarchy of the student submitting the work to the teacher for grading. 


\section{Technology and Issues with the Writing Process}

The writing process, as it is known in classrooms and among educators today, is “a private activity...broadly seen as comprising four main stages: planning, drafting, revising, and editing" (Seow 2002, 315). Research has also shown that "good writers employ a recursive, non-linear writing of a draft [which] may be interrupted by more planning, and revision may lead to reformulation, with a great deal of recycling to earlier stages" (Krashen 1984). Ernest Hemingway discussed his own rewriting process in a 1958 interview in The Paris Review: "I rewrote the ending to Farewell to Arms, the last page of it, thirty-nine times before I was satisfied" (Plimpton, 18). Another fiction writer, Roald Dahl (1945), similarly discussed the revision process in his book The Wonderful Story of Henry Sugar and Six More, stating, "You must be a perfectionist. That means you must never be satisfied with what you have written until you rewritten $[\mathrm{sic}]$ it again and again, making it as good as you possibly can" (105).

Other problems could possibly arise from the way inexperienced writers, especially those who have a different linguistic background than one which aligns closely to standard English, in the way they have been observed to view writing and writing on computers specifically. According to Sommers (as quoted by Hult, 2008), some students "understand the revision process as a rewording activity. They do so because they perceive words as the unit of written discourse" (327). By viewing it in this way, they become more fixated on finding the "right word" (especially when it comes to eliminating repetition in their writing) rather than looking at the entirety of their work: "student writers felt there was a predefined meaning that they need only find the right 
words to express, the experienced writers sought to discover or create meaning through the act of composing, and particularly through revising" (327, emphasis added). Unfortunately, research has shown that "word processing does not, by itself, encourage student revision" and that "word processing does not make student writing more correct" (326). Unfortunately, this problem is only exacerbated by the surface level corrections made by many popular word processing and writing software programs. For example,

inexperienced revising strategies may be heightened when students use text analysis programs, such as HOMER, HBJ WRITER, GRAMMATIK, or WRITER's WORKBENCH. Analysis programs concentrate on words and rewording (for example, vague words or sexist language), thus potentially reinforcing the inexperienced writer's emphasis on words rather than whole text" (328).

The future of writing instruction and literacy in general will, undoubtedly, require computers and some sort of word processing/writing software to accompany those computers. This is particularly the case as more states move towards AES scoring to replace human graders (for example, Florida, as reported by O'Connor 2014; and Montana as reported by Gunn 2008). In order to combat the problems noted by the research on the issue, teachers and computer programmers must find balance in their pedagogy and software development to discourage simple word insertion and deletion and instead encourage creativity, experimentation, and 'big picture' composition with an 
emphasis on revising rather than simple rewording. Allowing brainstorming and early note-taking or outlining to be composed in other languages and non-standard English would be one possible way to check that problem and develop a stronger foundation in their formal writing (Bean et al 2011). The existing writing software does not make room for that, but future software should be sophisticated (Perelman 2013) enough to identify semantic relationships between both languages being used and how to help students view their writing as the presentation of their own ideas being communicated rather than a presentation of words on a screen.

This problem was highlighted in Leung's (n.d.) manuscript “Automated Writing Instructional Tool for English Language Learners: A Case Study of MY Access" using the same software employed by the GMAT as one of its official readers (also the same program derided by Perelman and gamed using his "Basic Automatic B.S. Essay Language Generator, or Babel"). As described in the article, Leung fed "147 essays" from ELLs to "three writing prompts which were graded by trained EFL raters and MY Access"; of these 147 essays, " 15 randomly selected were also used for an error analysis comparing My Editor with human rater's annotations to examine My Editor's accuracy and usefulness" (Leung 2). Though high school students would most likely not be exposed to the GMAT, the article is still pertinent to this paper as it highlights potential problems of an AES in action and one being executed without human guidance during the writing process and partnering with the analysis provided by the AES. As previously mentioned, when students are given technology or have access to technology but are not given guidance and mentoring during that time, the benefits can be muted and are subject 
to become a new terrain for age old bad habits in writing, one of the bigger potential drawbacks of misusing the technology in the classroom. The problem with MY Access, similar to the problems exhibited in other similar research, is that the AES is treated not like a tool but as the be-all-end-all in the writing process. If teachers at the high school level were to treat that software in the same way, possibly to expedite things like grading and other functions, there would be no point in including it at all into the curriculum. If a teacher were to include it as one step to a final product, similar to how a calculator might double check steps along the way, there could be potential benefits. For a less motivated teacher, though, the factor of which program to use with students is of grave importance. For example, if the program were statistics-based (as described by Leung: "[they] create scoring models based on a large set of pre-scored essays of 300 or more" [Leung 4]), ELL students might be put at an immediate disadvantage because they are based off of essays written by students who, for the most part, are native speakers of English and have had enough success in the language and in education in general to elect to take a graduate school entrance exam. Hypothetically, an ELL/dialect speaking student could plug their essay into the program and be extremely discouraged by the results and from formal writing in standard English. On the other hand, teachers who have been working on information synthesis writing (document based questions and other Common Core style writing projects) might find "rule-based or knowledge-based" programs much more helpful due to their being "systems trained on a large domain-representative text such as textbooks or articles" (Leung 4). The results a student receives from such a program might not be as catastrophic as the statistics based model, as the chief focus of this type 
of software is to serve as a "scoring machine for discipline-specific courses" and one that "claims to be the only evaluation system in which meaning is dominant. Simply put, "it promises to help teachers and learners by evaluating essays based on what their authors appear to know about a topic" (Leung 4). By focusing on that aspect of writing, students could hypothetically have more opportunities for encouragement than discouragement in their writing; they might even possibly be more motivated to go back and do more reading to find which parts of the topic they 'missed' in their essay. But, like other challenges in this area of literacy, there is a catch, as some research has indicated that “the 'meaning' implicated by IEA [Institute for Educational Advancement] to totally disregard cohesion and coherence, which are of great importance to the meaning construction of every test" (Leung 5). The danger there, as Perelman (2013) has pointed out, even for the most vigilant of teachers, is that the students catch onto the game and try to plug in work that is a string of meaningless sentences and phrases that just so happen to include the domain specific vocabulary. In order to prevent this, teachers must make sure that students are plugging in actual work based on the information at hand. In some situations, it might even be beneficial to use two different programs in tandem: a basic and student-friendly grammar/spell check and a rule or knowledge based type of AES — the kind described by Leung above.

\section{Self-Efficacy and Increased Agency in Writing for High School Students}

The issue of self-efficacy and writing is intrinsically linked to the other issues brought forth by AES software and the possibility it presents in changing the revision 
process of writing, the chance to give students more control of and creativity in their writing, and the chance for students to develop writing in a low affective filter context. However, as noted by Sanders-Reio (2014), “Audience Orientation, a new belief associated with expert practice, was the strongest positive predictor of the students' grade" (1), thus presenting a possible obstacle in a computer assisted grading process in regard to holistic improvements in writing. Students, especially those fixated on their grades as opposed to learning or skill building, might try to fine tune their writing to fit the preferences of the computer (the perceived audience) as opposed to the teacher (the true target audience in this experiment). This harkens back to concerns of technology being improperly or ineffectively used in the classroom. As students become more accustomed to AES technology, they might treat revision sessions solely as an opportunity to figure out ways to trick the system into giving their writing high marks through plagiarism, their own style of BABEL writing à la Les Perelman (2013), or by focusing on little things like switching their words to "big words" instead of expanding the breadth of their ideas (Hult 2008). In order to negate the possible intrusion of the computer as the target audience for the student instead of the teacher, extra care must be taken so that the teacher maintains their position in the classroom as that of the expert in the eyes of the students.

On the other hand, the obvious benefit of using this technology in the middle of the writing process is that it gives students instant feedback with which they can review and revise their essays (PaperRater 2016). This ties back to Sanders-Reio's (2014) report which highlighted a variety of studies claiming that writing is a recursive process that 
requires students to continually go back to their work and revise; Murray (1991) even went so far as to claim that "Writing is rewriting" (3). The role of the computer, in this sense, is to give students the opportunity to create more space for them to compose ideas without the fear of reprisal in the form of a poor grade or other punitive measures which hinder the writing process. The computers, if used correctly, could create several key phenomena:

1. A buffer zone between the students and teachers that both parties may enter for the sake of improving the specific writing project of the student without worrying about whether or not the student was paying attention to a lesson (a common worry of teachers),

2. A presumption by the teacher that the student has poor writing abilities, or

3. For ESOL students, a poor command of the English language (common worries and obstacles for ELLs).

Self-efficacy is defined by Sanders-Reio (2014) as “confidence in one's ability to perform tasks required to cope with situations and achieve specific goals" (1). In writing, self-efficacy can be increased through this buffer by allaying feelings of apprehension, anxiety, and helplessness. When the tools to grade and assess student writing are put in the hands of the students themselves, there is a chance they will not only use it as an asset to get the types of results they want but also that they will work and re-work their writing, as Hemingway and Dahl recalled, and improve their writing without even doing so consciously. There is also a chance that essay writing is not seen by students as simply a 
test wielded against them but rather as the process through which their formal writing skills become honed through the benefit of having insider knowledge of a major part of the process (grading and assessment).

\section{Related Potential Approaches to Improve Student Writing}

Another method of evading the types of problems that arise from low self-efficacy, as well as a way to make sure more students get valuable guidance and instruction, is to work with peer tutors or college students. In Palacio's (2011) article featured in "The Successful High School Writing Center" put forth by the National Writing Project, a teacher in Miami decided to establish an after school writing center at the high school where she worked (Monsignor Edward Pace High School) after noticing the struggles her students had with writing. The majority of them (if not all of them) came from homes where English was either not spoken ("seventy percent of Pace's students is Hispanic, and so when our students leave school, many return to homes where Spanish is the primary_or only_language of communication" [Palacio 20]). The surrounding area is predominantly African American and Haitian/Haitian American, which also presents issues with standard English at school. Palacio decided to establish the writing center after "feeling their frustrations [with writing] intensify" during a typical writing assessment and the observation that "to most of [her] students, writing equals grammar, and grammar equals bad grades" (Palacio 19-20). Palacio reached out to St. Thomas University, a Catholic university in Miami which "shares a fence" with 
Monsignor Pace (20), and their University Writing Center Director to coordinate a program which would send college students to the high school to help students with their writing. Those college students in particular were also chosen due to the fact that "many of St. Thomas' students share the same language and/or cultural background as Pace's students, [so they] knew the tutors would likely be able to relate to [Pace's] students" (21).

The idea of peer tutoring also coincides with much of the ideology behind differentiated instruction and small group theories, theories which are gaining traction in the United States (Gillies 2004, Palacio 2011) . With writing instruction in particular and the inclusion of computer technology before a final draft is submitted for grading, collaborative learning can create the foundational 'background knowledge' touted in schools and create more student friendly learning environments: "The notion of conversation-infused writing centers has led some to imagine a Burkean Parlor in which the conversation is never-ending: Students enter the parlor, listen, contribute, and move on, only to be replaced by new students who enter, listen, contribute, and move on...Throughout it, students learn to negotiate power and control” (Rafoth 2011, 11). Doing so can facilitate higher order language as well as meta-cognitive processes. In fact, Rafoth suggests that peer tutoring functions in the same way except that it replaces the entire classroom conversing with individual or small groups of students having those "Burkean Parlor" never-ending conversations with one leader (teacher or tutor). As mentioned before, it is not always practical to expect tutors to be on call and ready to tutor at the drop of a hat. Instead, the focus must shift (when discussing classroom 
settings anyway) to methods of including those conversations and more relaxed contexts into classrooms while still maintaining order. This could be accomplished by breaking the students up into smaller groups, engaging in activities such as debates and Socratic circles, or by playing games that the entire class could participate in. Doing so will foster growth in not only their spoken language, but their written language as well (Rafoth 2011).

\section{Noticing}

Writing teachers can merge the theory of collaborative learning (Mulqueen 2011) with computers by setting up the students to do more noticing, something which is a "key concept in second language research and one developed by Richard Schmidt (1990), who realized as he was learning Portuguese that he had to notice something before he could learn it" (Rafoth 12). Students who speak a different language or dialect at home could greatly benefit from this concept in application because they are given more agency in their language acquisition and are encouraged to share ideas with their classmates. When noticing is working well, students are able to move past being a tacit audience to being masters of their own minds, internalizing information presented to them. From there they are more likely to use that information and self-confidence and in their writing. This concept is also described by Schmidt (1990) as “what doesn't get noticed doesn't get learned" (238).

Noticing is a concept which could be strongly applied through new technology as well. According to Palacio (2011), students may tend to care more about their grade and 
the topical errors of their writing rather than seeing the bigger picture in their work. Palacio also noticed nervousness, anxiety, and frustration from students preparing to hand in their work to the teacher. If students were allowed to use AES and revision assistant programs before handing in a final product, they would use the same mechanics involved in noticing and apply them in private on their computer screens by seeing suggestions made by the software. Students could even (depending on the maturity level of the class involved) share among themselves the notes given to them by the software and see the similarities and differences between other student writing. The issue of noticing will be further discussed with respect to dialectal issues later in the chapter.

\section{Self-Efficacy in High School Writing}

Academic writing is a skill which requires confidence, control, patience, empathy, and self-efficacy to achieve the kinds of results students at any level desire. The role of teachers in helping their students reaching those goals can be dubious in the perception of the students, as at times they may feel the role of the teacher is to hassle them and tell them how they are wrong, rarely how they are right or show ingenuity, as may be described by under the umbrella of Krashen's (1982) Affective Filter Hypothesis. Krashen states that a higher affective filter is due to negative emotions such as fear and shame, therefore students may be less likely to learn and develop their language skills in the target language. The same can be said for writing in particular, as students can become paranoid about teacher notes and immediately tie them to a grade and negative 
performance review rather than genuine suggestions for improvement (though sometimes the students' intuitions may be correct) (Matsuda 2011).

\section{Issues of Linguistic Bases for High Level ESOL students}

\section{Affective and Social Barriers for Students and the Use of Home Languages and Dialects}

There is research, however, that indicates that there is a similar problem with the issue of bias but on the part of the students. According to Pennington (2011), if students experience technical difficulties when trying to use computers or software, they "may have their enthusiasm dampened if they experience technical problems early on, have difficulty typing or mastering computer commands, or have limited access to computers and to experienced users who can offer assistance when things go wrong" (Pennington 2011, 304). A major real world example of this was during high-stakes testing in the state of Florida for the 2014-2015 school year, the first year of the new Florida Standards Assessments (replacing the FCAT). Unlike the FCAT, which had both paper and computer components, the new exams were done solely on computers, and despite this new protocol, no school districts nor individual schools were checked to make sure the extant technology was capable of administering the tests. The tests ended up crashing computer systems and networks throughout the state and the news was littered with reports about how students "did not take the test as seriously" (Veiga 2015). In order to 
prevent such a problem, schools need to be technologically updated as they need to be. However, since funding and needs among schools differ, programs such as AES could therefore be implemented to scale in terms of available technology (number of devices, speed of internet, etc.) and in terms of the computer literacy of the students rather than with a one size fits all approach (Wong 2014). Schools without large computer labs or modern upgrades should not force their students to attempt to use the same writing technology as schools that do have those amenities (hopefully that would be a given). Instead, that school could use a mix of paper and a technology rotation to ease the technological load of the computers and to allow each student ample time to work on a computer that is not being stretched to its absolute limits. Setting up a scenario in which students are allowed to work on a writing project using technology that works is almost as important as them using any technology at all (Postal 2016; Blume 2014). Additionally, many students do not have computers at home (Monahan 2014).

Another method of stress alleviation and accommodation for ELLs is the allowance of them incorporating their home language or dialect into their writing (Bean et al 2011). Though such an approach may seem counter-intuitive to ESOL education, particularly in the era of massive implementation of high stakes standardized testing, some studies and anecdotal reports have shown that allowing students to incorporate their L1/home dialect in the writing process can help them both understand and achieve higher levels of formal standardized English (Cummins 2001). Bean et al (2011) showed that "students who write in a dialect of English can usually retain more words and syntactical constructions from their drafts when they revise into standardized English than from 
drafts in a different language... [they] seem better able to harness the strengths of voice as they revise into standardized English" (Bean 233); also, "there is research showing that the use of L1 by ESL and EFL students may help in fluency, organization elaboration, and retrieval of ideas during L2 composing [reference to said research followed this claim]" (Bean 234). For many ELLs, mastering formal writing in English has been hampered by a lack of finely tuned understanding of those same "syntactical constructions" (Bean et al 2011, 233) which are typically different from the way the language is commonly spoken. For students who speak a dialect of English, especially stigmatized ones such as African American Vernacular English, Caribbean Creole English, and Hawai'i Pidgin/Creole English (Bean 233), research has shown "how rhetorical features of African American Vernacular English (AAVE) served to improve the scores of student papers on NAEP exams...[there are possible] benefits for AAVE students [starting] writing tasks in AAVE and then revising to the dominant variety of English" (Bean 232).

The major roadblock for teachers trying to put that research into action is simple but easily avoided. Were those same students to write in their L1 or home dialect onto a computer, the spell check and grammar check that serve as features on nearly all modern word processing software would mark up their writing with "errors" (Christensen 2003). However, if they were to write out their early drafts and notes by hand and then use writing software to compose their final work in standardized English, they would not only be able to see improvements in their test scores but also compare in real time the fluency and syntax in their home language/dialect to standard English. Teachers choosing 
this path must be well prepared, though, and trouble might arise if they have absolutely no familiarity to the linguistic backgrounds of their students.

\section{Summary and Suggestions}

A summary of the literature indicates that the overall use of AES programs will continue to expand, but there are lingering issues when they are the sole evaluator of a written work. One could imagine, for example — when implementing the rules of AES grading and its preference for verbosity - that some of the terse and punctuated prose of The Lost Generation (Faulkner, Hemingway, Steinbeck, etc.) would probably not score well today despite their standing as some of the preeminent literature in the history of the United States. As Perelman (2013) might suggest, good writing is good writing, and computers may never be to the point where they can make the same judgments as the trained human mind can regarding the quality of a piece of literature. However, what all of this means is not that we should eliminate the idea of using them altogether nor that we should wait for the technology to catch up in a sense. Rather, it means that we should not consider current technology as a human replacement but rather as a helper. If approached the same way as a calculator in a math class, this technology could plausibly provide ELLs and dialect English speakers the privacy and power over their own work they need to find more success in their writing before turning it into the teacher. As noted earlier with respect to Dwyer and McCloskey's (2013) comments on background, all TESOL teachers should have (at least) a basic understanding of who their students are and why they ended up in their classroom. And, as also noted earlier, teachers cannot expect the 
writing process to manifest itself through technology nor should they expect students to understand the language of technology without having someone guide them along the way (Hult 2008). Taking away those opportunities for language acquisition and technological literacy comprehension would be a grave disservice to students, especially to those who do not have access to the same technology at home.

In order to see this ideology implemented in schools across the U.S. to some degree, several steps and precautions could be taken:

Teachers must understand the demographics of their students both in broad terms and specific terms: this includes country of origin as well as some semblance of understanding of why they left their country and culture behind (Dwyer and McCloskey 2013).

If their students speak a dialect form of English at home, they must, at the least, understand and respect the role that plays with their literacy development and see it as a tool to master standard English, not become an obstacle. This can be done by allowing them to make early drafts and notes in their home dialect (Christensen 2003; Bean et al 2011).

Writing software is not yet at the point where it can be treated as the be all end all for grading writing. Human graders must continue to have that authority until there comes a time when computers are sophisticated enough to detect nuance in writing, not just basic grammar, lexical, and syntactic features (Perelman 2013).

Computers must still be a part of writing classes, but must be done so in a way that coincides with the affective filter theory and does not become a crutch (Krashen 
1982). Research indicates that students will not respond well to writing software and word processing use if they are not provided with guidance and instruction along the way (Hult 2008).

The theory being put forth by this paper is that the best use for computers in writing classrooms is more akin to a calculator than a machine of finality. Students should be allowed to write, plug in their written work into the program, and make changes based off the suggestions of the software. They are purely suggestions because the AES and word processing software are not ready and will probably never be ready to replace human educators (Perelman 2013).

Peer tutoring is an effective means of providing the necessary guidance on both the computers as well as formal writing in general (Palacio 2011). Even for people who might not have the same linguistic background, they might be able to relate in deeper ways based on other factors such as age, neighborhoods, and mutual friends or associates (Ovando and Collier 1998; Bean et al 2011; Palacio 2011; Mulqueen 2011).

Writing software has great potential to alleviate a wide variety of issues for students who speak other languages and dialects at home, but if it is not done properly or is done hastily, the purpose of including the technology into the syllabus could be lost, and students might find themselves with even more difficulties than they started with. Teachers should be patient (Ovando and Collier 1998), and if they can apply the theories and methodologies put forth by the research, their students will be the ones who could be the ultimate benefactors. 


\section{Review of Haitian Creole}

Thus far in this literature review, a key point of emphasis has been teachers' knowledge of their students' backgrounds, including information regarding their home cultures and languages. A primary focus of this research is the role of Haitian Creole as it pertains both culturally and linguistically to the students within the study. This section examines the depth to which Haitian Creole could be contemplated while assisting students with writing in academic English.

Haitian Creole (Kreyòl) has been the source of debate for linguists, sociologists, policymakers, and educators in regard to its status and its position in the Haitian community in relation to French. My experience as a teacher in Miami shows that among second generation students in Miami, Haitian Creole is frequently described by students and even teachers as "broken French" or "not a language", much in the way Ebonics has been described as slang in the U.S. and not a true language (Ebonics Site n.d.). These beliefs, however, do not have their genesis in the U.S. but rather in Haiti itself. Despite its equal status as one of Haiti's two official languages and despite the fact it is spoken by an estimated $90 \%-95 \%$ of Haitians (Valdman 2000), French has a strong hold as the prestige language. It is often said (and easily verified) that French is used in the business sector, as the language of education at all levels, and is the language of politics, and, to some extent, the language of church. This effectively boxes out the vast majority of the people of Haiti from active leadership and participation from those sectors, even though it is estimated that as many as $42 \%$ of Haitians speak some degree of French (Organisation Internationale de la Francophonie 2014). Students who emigrate to the United States with 
their family are directly affected upon arrival because of the prevailing misconceptions - in line with Ferguson (1959) who claimed that "every Haitian is more or less bilingual" in Haitian Creole and French — of the linguistic realities that people contend with on the island.

\section{Prestige Language Use in Haiti}

Despite what some may believe, Haiti actually "fails as a case of classical and strict diglossia" (Dejean 1993, 73): In order for a society to reach a classical diglossia, everyone or nearly everyone needs to be effective communicators in the languages at hand. For the wealthy and powerful in Haiti, such a phenomenon exists: While on the campaign trail, President Michel Martelly spoke in Haitian Creole to rally support for the candidate representing his party (while I was in Haiti, I witnessed this myself); but when dealing with his internationally connected constituents, speaking with the international community, or disseminating government mandates online or through the media, his language of choice was French. For Haitians today and in the past, the first impenetrable barriers that Haitian Creole faces as a language have been in the educational system, as all education and official educational information in Haiti is conducted and produced in French, from primary school to university courses (Degraff 2010).

The separation and segregation of French and Haitian Creole began during the French colonial era in the Caribbean as served as "the language of the ruling class," and "French planters and their colonial establishments" (Zéphir 2015, 120); Creole was the language of the "plantation slaves," the Creole slaves born in the colony, and the slaves who worked in the habitations (homes) of their masters who also exhibited some 
proficiency in French (120). At this time, French also established itself as the language of any and all formal affairs, setting a precedent in language that is still in effect today. Social stratification historically and contemporarily also has strong reflections through language: the more education one was and is able to attain is usually apparent through their proficiency in French. Unfortunately, the issues of linguistic inequality have been compounded over time as Haitian Creole was the "language of the uneducated, dominated masses, which are excluded from meaningful participation in Haitian society" (120). The genesis story of the language is often mentioned as the result of people speaking "broken French" or people who were not intelligent enough to understand it (Spears 2010). By having this type of story - in contrast to other language genesis stories - and disseminating it to both native speakers and outsiders, native speakers of the feel that their mother tongue is inherently deficient. This belief also plays out in the severe lack of reading material in Haitian Creole (DeGraff 2005, 2010).

In Haiti, the vast majority of books, all newspapers, all official information (such as street signs, technical instructions, archival materials, safety signs), and all business documents are in French (Perry 2000). Aside from the issue of the perception of prestige among people on the island, there is the issue of non-uniformity (for example, road signs, business signs, or public messages) in Haitian Creole orthography, spelling, and grammar. However, depending on where one is in the country and who is writing the sign, things like pronouns, the gerund marker, the past tense marker, and even articles might be spelled differently or rearranged in different ways. French, on the other hand, rarely has such issues and is governed by the Académie française (French Academy), 
thereby ensuring all documents can be written uniformly and be understood by the entire global Francophone community. Due to the preference of the French language in Haitian schools, Haitian Creole does not enjoy the same uniformity and suffers in fundamental ways because of it (Zèphir 2015). The seeming lack of organization in contrast to French also contributes to the mentality that French is 'above' Kreyòl, and despite efforts from the Akademi Kreyol Ayisyen (Haitian Creole Academy) to standardize the language and educate the people in it, little headway has been made. Despite historical efforts to improve education and to "(1) to open educational access to all citizens, irrespective of socioeconomic status and geographical areas; (2) to improve "the internal and external efficiencies" of the educational system; and (3) to effectively establish Creole as a primary vehicle of instruction, especially in the early grades" (Zèphir 2015, 121) during the late 1970s, the fact remained that the ruling class has not adopted any of the changes themselves and continue to use French as a means to dominate the masses. For as long as those in power do not allow Haitian Creole to rise up in stature, it will be difficult to foresee a change in the near future.

There are some modern grassroots movements focused on changing the language of education from French to Haitian Creole (Degraff 2010). Due to the many claims, studies, and anecdotal evidence pointing to the flaws of teaching its citizens in French (the most noteworthy reason being the teachers themselves have a weak grasp of the language), smaller communities and villages have taken it upon themselves to lead the fight for equal standing. Though the road to linguistic equality will be long and arduous, 
there are several key players and institutions giving their full support of the movement in the last several years:

Linguist Michel DeGraff has devoted the bulk of his academic work to the advocacy of Haitian Creole, which, he has argued time and time again, is a language just as sophisticated as any other language...Albert Valdman...has called for the development of authoritative Haitian Creole dictionaries, and other teaching materials in Haitian Creole...[Furthermore] Haitian linguist Pradel Pompilus from the early 1960 s to the early 1980 s on the linguistic description of Haitian Creole (phonology, morphosyntax and lexicon)...The fundamental role of Haitian Creole in the school system has received momentum in post-earthquake Haiti, thanks to a great extent to Degraff's works, who has the full support of the Massachusetts Institute of Technology” (Zèphir 2015, 125).

The summation of these comments indicates that undoing years of negative connotation of the language and the condescension against it requires the work of many. Though there are many people fighting for the dignity of the language, it still requires extensive efforts to elevate it. The condescension and fight for dignity resonate in light of French, which has a far longer linguistic and educational history than Haitian Creole. 


\section{French vs Haitian Creole}

Amid all of the debating of language policy in Haiti, the fact remains that the languages are simultaneously intertwined yet diametrically opposed. French is a Romance language that was influenced by Gaulish during the time of the Roman Empire (Lodge 1993). After a successful takeover of what is now France during the reign of Julius Caesar, the Romans brought Latin with them. Some lexical influences from Gaulish were retained, but Latin became the dominant language. Around the third century, the area was invaded by Germanic tribes (the Franks), leading to more influences on the language, especially in regard to social terms (political, military, farming), prefixes and suffixes, and the frequency in French (more so than in other languages) to place the adjective before the noun (Lodge 1993). There were other influences between then and the Oaths of Strasbourg (the first written example of Old French) as well, primarily from other marauding tribes from the surrounding areas (Lodge 1993).

The story of Haitian Creole is far murkier and does not have the benefit of 1,000-year-old documents left behind for researchers to analyze. Though approximately $80 \%-90 \%$ (depending on who you ask) of the lexicon is derived from France, some linguists feel, and rightly so, that "its syntactic typology more closely resembles that of Gbe languages" (Grant 2011 referring to Spears and Joseph 2009). There is debate amongst scholars regarding the origin of the language in as much there is debate as to how creole and pidgin languages come about at all to begin with (Singler 1996). The case for Haitian Creole is complex, as some believe the language actually originated in trading 
posts in West Africa and others who believe it developed in Haiti itself (Singler 1996; Spears 2010). There is consensus, though, that the shift from tobacco and cotton farming to sugarcane increased the need for slaves which subsequently increased the number of people learning and proliferating the language (Lefebvre 2006).

Lefebvre (1986) indicated that the key distinction between Haitian Creole and French, aside from pronunciation, is grammar. Much like the Fon language spoken today in Benin and Togo, Haitian Creole places definite articles and possessive markers after nouns. For example, to say "my car" in Haitian Creole, one must say "machin mwen" ("car my"). To say "the car", the definite article is placed after the noun: "manchin nan" ("car the"). Tense markers are also placed differently. Instead of being placed after the word being modified, they are placed in front: to say "I am eating", the gerund goes in front of the verb, "Mwen ap manje". Pronouns take on more roles in the language, as there exists only one set of words that is used for all situations. For example, in English

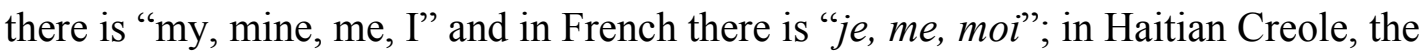
word " $m w e n$ " and its contracted form of " $m$ " is used in every situation. This can become one of the basic problems with Haitian Creole speaking students being thrown into the French speaking classrooms of Haiti as well as for immigrants to the United States. The other major fundamental issue and difference between French and Haitian Creole is the "to be" form; in French, the "to be" verb is conjugated and used frequently. Haitian Creole does not have any conjugation and uses the "to be" form much more sparingly and almost as an intensifier. 


\section{Accounting for Home Language and Dialect}

Once the intricacies of language and dialect have been considered, setting up a syllabus is important. Generally, many students who speak languages other than English at home (especially many Spanish and Haitian Creole speaking students) or dialects of English which are usually marginalized or often stigmatized (African American Vernacular English and Caribbean Creole English dialects or even accents in Miami) come from homes where there are basic family issues (single parent, foster home situations, living with grandparents, etc.) or basic financial issues (unemployment, underemployment, working the night shift, working multiple jobs, etc.) (Bean et al 2011). Even within the more general Spanish speaking communities of these areas, some dialects (especially Puerto Rican, Dominican, and Mexican dialects) are looked down upon in favor of other dialectal forms (Suárez Büdenbender 2009). Unfortunately, many of the schools these students go through prior to reaching high school "do not necessarily provide adequate resources [and] personalized support is imperative to their academic growth and success" (Mulqueen 2011, 28).

In Miami, for example, most schools do not have Haitian Creole to English dictionaries (and the most commonly used one is a small volume designed more for practical speaking purposes rather than formal writing) if they have anything at all specifically for Haitian students (anything else would be a French to English dictionary even though Haitian Creole is $\underline{\text { not }}$ French nor mutually intelligible with French). In addition, these types of students are not exposed to the types of conversations and 
language being used in the homes of people like native English speaking Americans, the professional and middle class, and from other homes where the English necessary to succeed in writing and school is being spoken with even a modicum of semblance to the language necessary to perform well at school. Facilitating that process in the classroom can only do so much, but when done well it can make a huge difference in their writing. Doing this requires a teacher who "encourages students to talk with them about their work, their goals, and their struggles to get ideas down on paper" (Mulqueen 2011, 29). Opening up the lines of communication between the teacher and student will also serve to fill some of the one on one language they are missing out on at home (for whatever the reason may be). However, this process requires patience, and instead of allowing something like the results from AES to become the final word on a student's performance, teachers must work into the rubrics and scaling a means to recognize the progress they are making. For example, by "using a multi-draft process, a teacher learned to look for a student's progress. He/she understood that final drafts that at first glance appeared unsuccessful might actually be testament to monumental progress, so he/she built into each grading rubric a score for improvement" (Mulqueen 2011, 29). To enhance that same "monumental improvement," computers could be used to provide students with the necessary collaboration and agency in their own writing to make even bigger leaps and bounds by introducing another revision step into the writing process (as mentioned before, this can only be done so if it is done right in the ways the research suggests). This also must be attempted with the idea that the affective filter is an important factor in L2 acquisition or the acquisition of standardized English from dialect 
speakers of the language. This could require, as was the anecdotal case of a high school peer writing tutor, someone who is "patient, clear, and concise" and one who is not "flustered by the language barrier" (Mulqueen 2011,32). Giving each student the time of day they deserve as a part of their education will have noticeable effects on their writing. High school students generally want to learn and do well (when situations in the home life or mental health issues are not too much for adolescents to overcome), and by giving them breathing room and agency, they will be able to do just that.

\section{Synopsis}

Effective, engaging instruction for ESOL students can be a difficult task. The task becomes ever more complicated when it comes to the complicated language of academic writing (for non-ESOL students as well). One potential way to improve academic writing may be through the alternative use of AES software: using it as a step in the writing process rather than the final grader. This might also enable the students to do more "noticing" of the language around them by introducing corrective feedback without worrying about their grades. This could also help certain student groups, such as Haitian-Creole speaking students, feel more empowered in their rhetorical language skills. For years they have been maligned and misunderstood in Haiti and the US in educational settings. The objective of this project was to identify how Haitian Creole speaking ESOL students report their experiences by giving them a tool through which they might feel successful and learn from. The implications of this inquiry may shed light on the potential for overcoming some of the traditional problems these students face in 
schools. The same may even hold true for students who speak marginalized dialects of English, such as AAVE and Caribbean English. The conceptual framework of this project is drawn out in the figure below.

Fig. 3: Three-Pronged Conceptual Framework

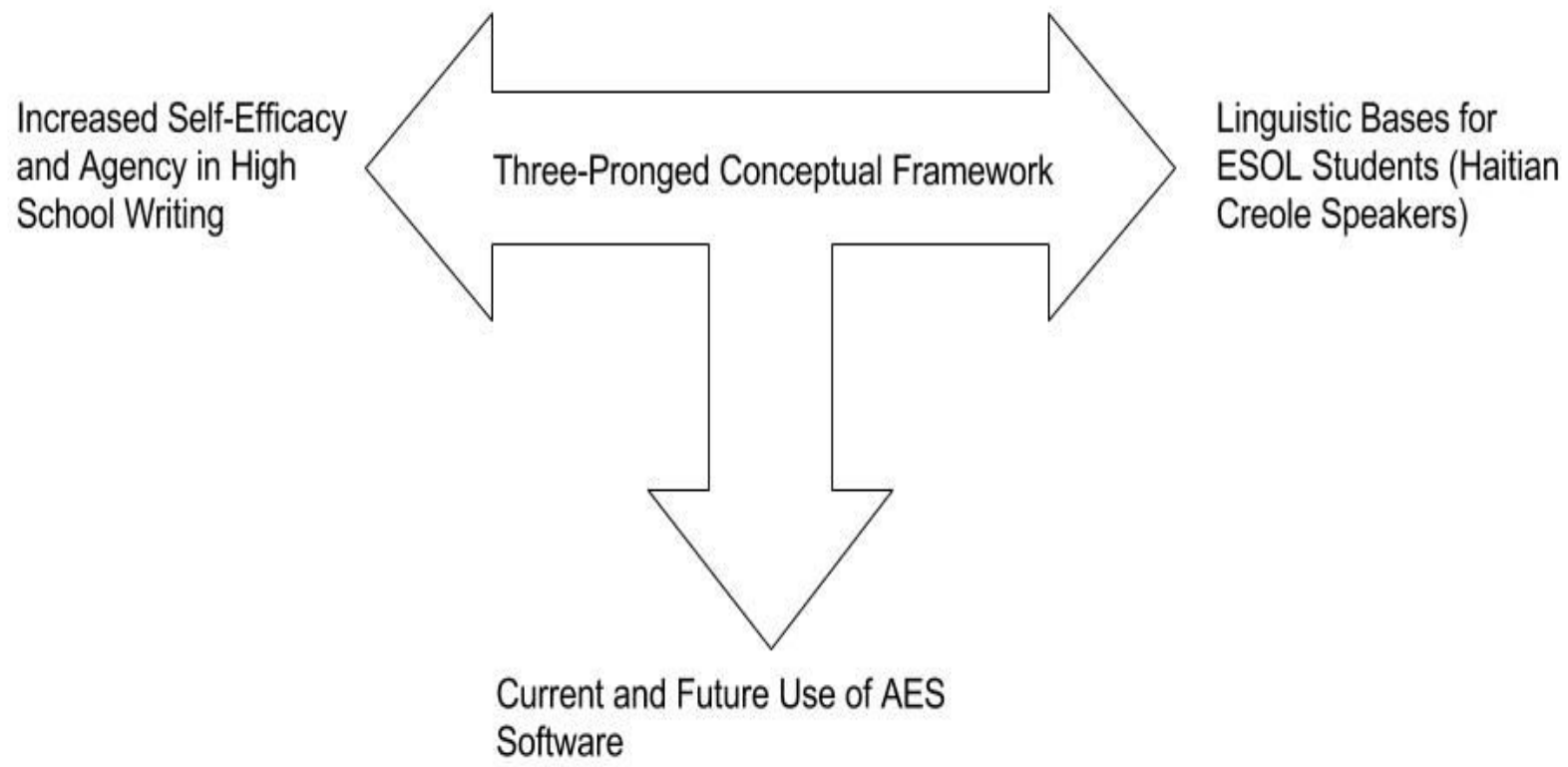




\section{CHAPTER III}

\section{METHODOLOGY}

\section{Introduction}

The main points of this project were to utilize AES technology in the middle of the writing process rather than using it as a grading tool; to allow Spanish speaking and Haitian Creole speaking students to use their home languages as part of the writing process, if they like; and to see if using this technology can increase students' feelings of self-efficacy and agency in their writing. This chapter will outline the pilot program and results of the questionnaire.

The experiment and methodology for this project were direct and designed to be the first step to answering the questions of whether or not AES software could be used as a classroom tool to improve high level ESOL student writing; to measure the response of the students to having a teacher who spoke the same languages as they did at home (especially for Haitian students); and to determine if using AES type software in the middle of the writing process instead of at the end can create opportunities for high level ESOL students to be more efficacious in their writing.

\section{Research questions}

The research questions focused on two critical aspects in modern education in the United States: students who speak languages other than English at home and the use of 
technology in the classroom. These issues are prevalent across the curriculum, but these questions focused on how they play out in English Language Arts classrooms. Much of this project began with the ideas that AES software can be repackaged right now as a revision assistant tool for students to use as formative feedback to assist with the revision process as well as facilitate more writing/rewriting overall. It also began with a separate hunch that the best way to help Haitian/Haitian-American students achieve more success in school would be to learn Haitian Creole to better connect with them and understand where gaps might be linguistically. As a result, this study posed the following research questions:

1. When using AES software as a tool in the writing process, do high level ELL students report an increase in their sense of self-efficacy as a result of revising of their work?

2. Do high level ELL students report, as a result of writing essay outlines/notes in their home language (especially Haitian Creole), an increase in their feelings of confidence when writing their final drafts in standard English?

\title{
Research Design
}

\author{
When using AES software as a tool in the writing process, do high \\ level ELL students report an increase in their sense of self-efficacy as \\ a result of revising of their work?
}


The first question regarding an alternative use of AES software as a classroom tool to enhance the writing performance of students has been investigated by Warschauer (2007) and by SRI (2015). They both found that teachers and students are agreeable to its alternative use as a classroom tool to use in the middle of the writing process. This project also used an AES program in the middle of the writing process to see if the students would have similar reactions. This research question was investigated through this lens as a possible solution to the issue of students treating revision as a word-switching activity (Hult, 2008; Kolowich, 2014).

\section{Description of Paperrater.com}

For this project, the AES program implemented was paperrater.com. It was selected from a primary list of options that came from a flyer with the names of free online AES programs distributed as supplementary material to a presentation at the TESOL 2015 conference (see fig. 2). The list included names of websites that were free for anyone to use. Though there were more sophisticated programs (as previously mentioned with Warshauer 2007 and SRI 2015) that would have given the students a 'writer's workbench' type experience, none of those types of services are currently free. These include Pearson Writer, WriteLab, and Turnitin.com Revision Assistant (formerly LightSide Labs). The allure of these workbench programs is that they create a space where writers can compose, take notes, search articles (similar to Google scholar), and have more detailed feedback to student writing compared to the free websites. In fact, an attempt was made to bring in WriteLab to the school but funding was not available. 
Paperrater.com was eventually selected from the free websites for its straightforward interface, comprehensive but not overwhelming feedback, and ability to be graded on a system students were familiar with (a traditional 100 point scale).

Fig. 4. Pro/Con Handout from Lippincott and Fuentes-Anderson at the TESOL

International Conference 2015 (Used with permission)

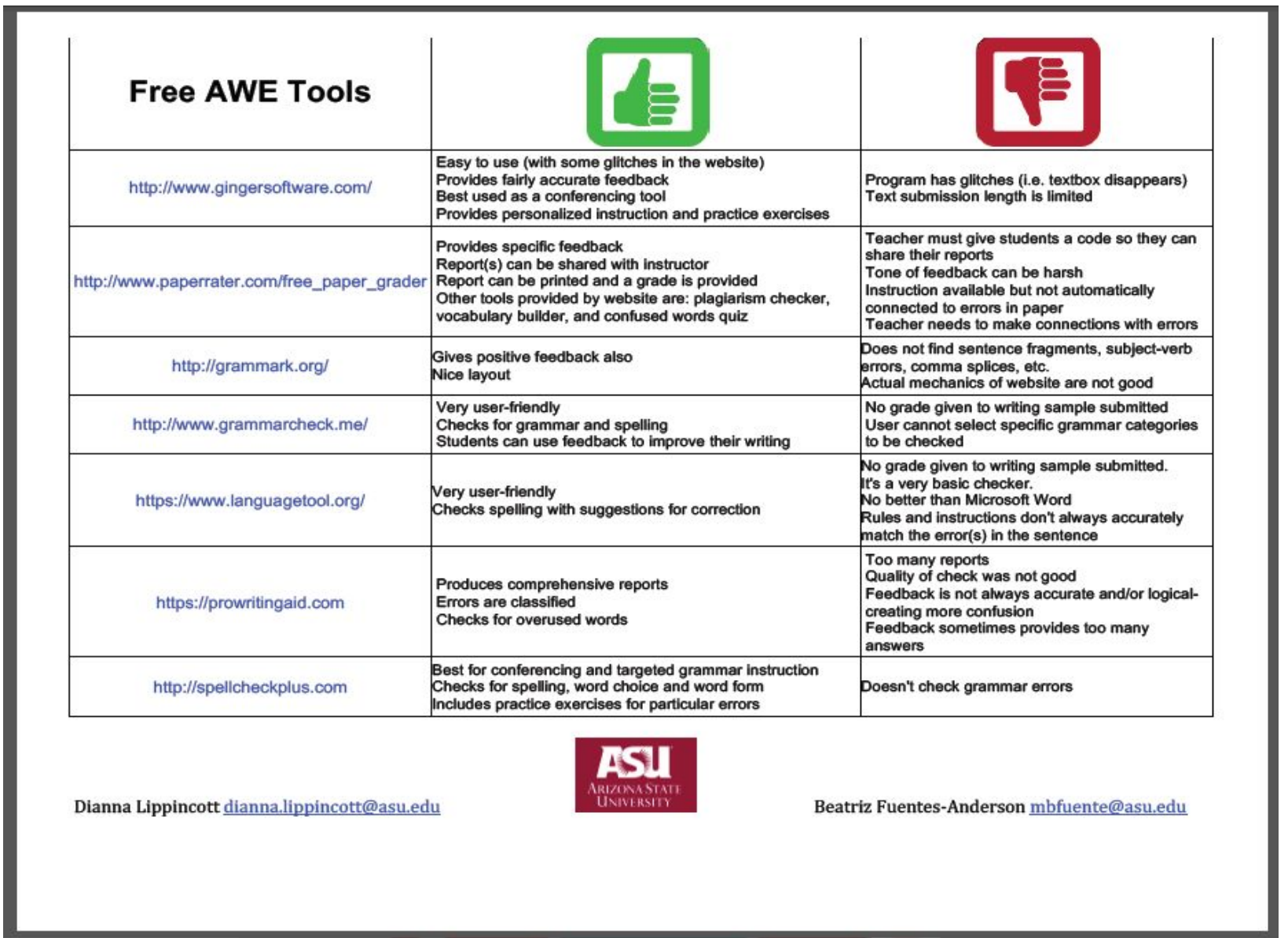

Paperrater.com is a "free online tool developed and maintained by linguistics professionals and graduate students" (Charya et al 2015, 24) that focuses on content and 
plagiarism detection. The program detects plagiarism by seeking similar phrases or sentences from " 20 billion pages" on the internet indexed by Google, Yahoo!, and Bing (Charya et al 2015, 24; Paper Rater 2016). Once the plagiarism search is completed, an "originality score is calculated within seconds," (Charya et al 2015,24) with a low score indicating that the material had a strong match to a source found through one of the above search engines. For example, if a sentence were to be directly copied and pasted from an online source material and included in the essay, regardless of how it is cited in the essay itself, the "originality score" would be pinged. This feature also played into the decision to use paperrater.com, as one section of the Florida Writing Rubric (Florida Standard Assessments 2014) deals with the effective incorporation of specific examples from source materials as well as explaining how it bolsters the main claims of the student's essay. This could include using the same jargon or terminology as well, something that the students should be doing in their essays and something that could provoke another ping from paperrater.com's system.

The program developed by the paperrater.com creators uses computational algorithms, artificial intelligence, and natural language processing programs to assess essays submitted to the website (PaperRater 2016). Each essay submitted is analyzed on its own instead of being compared to previous essays written and submitted. This is another unique feature to the website, as other revision assistant programs and prototypes, such as the software being developed by Turnitin.com (Turnitin.com 2016; Warschauer 2015, personal contact), depend on previously written and graded essays to make comparisons and value judgements. For example, a website using this type of method 
might have 100 essays that were assigned a perfect score, 100 with an average score, 100 with a low score, etc. Any new essay submitted would be analyzed and compared to those other essays, and if the software determines that the new essay is comparable with a perfect essay, it will receive the same or a similar grade. Also, as noted by Lippincott and Fuentes-Anderson (2015), the feedback from paperrater.com was specific, shareable, and came with a numerical grade that students can easily understand (0-100, A-F scale).

Though this particular program might not be as strong as others in terms of encouraging students to make holistic revisions to their essays, it still fits the needs of the project, fits well into the setup of the writing classes, and is free to use.

\section{Do high level ELL students report, as a result of writing essay outlines/notes in their home language (especially Haitian Creole), an increase in their feelings of confidence when writing their final drafts in standard English?}

The second research question will be investigated through the experiment and subsequent questionnaire, but anything beyond that will be determined by the students themselves. It could be a situation where every student or no student opts to use their L1. Their feelings about having a teacher who speaks their own language will also be assessed through the questionnaire. The article regarding students using their L1 or vernacular forms of English as part of the writing process by Bean et al (2011) provided a strong framework this project attempted to model. 


\section{Population and Sample}

\section{Structure of My Class and Implementation of Project}

My classes all focused on essay composition, and passing the state writing exam was the chief goal for each of my students. Of the six sections I taught, one of them was comprised entirely of ESOL students at level three or four, meaning that they would probably be the next batch of students to pass the state mandated tests in order to leave ESOL (ESOL levels one and two are considered emergent learners). These students were the main focus of the project. Dispersed throughout my other classes were 'mainstreamed' ESOL students who had been designated as ESOL at some point. For some, this was their first school year of not taking ESOL classes; for others, they transitioned out long ago or tested out upfront and never had to take an ESOL class (such as developmental English, ELA for non-native speakers, etc.). After finishing a larger essay project, students were given writing tests once a week or once every other week and then conferenced with myself or the literacy coach immediately after. The students were also given laptops and were required to type the essays they had written as well as make revisions before using the AES. For this project, students were invited to compose notes and outlines for their essays in their L1. After, the students used the AES software to continue the revision process and collaborate with the teacher to come up with the the

final draft. The technology was introduced to them right before the quick writes started, 
making the focus on the big essay project they had been working on. Afterwards, the questionnaire was given to them and they answered the questions.

The classes met for 90 minute blocks every other day, though adjustments were made as a result of state testing.

\section{Physical Settings}

Students were in a class which followed a scripted format provided by Miami-Dade County Public Schools. Though there was some room for differentiation, the strategies and expectations were uniform across the school district, and the ultimate goal (according to the 2015-2016 School Improvement Plan) was to get as many students to pass as many tests as possible. With that said, all of the data were collected during regular class sessions and based on the state writing rubric for academic writing. The school is located in northwest Miami Dade, an area all too familiar with academic struggles. Just last year, $17 \%$ of the students at the school scored proficient or higher on the state ELA exam (combined scores of the reading and writing tests) (Florida Department of Education 2016). The school serves the communities West Little River, Opa Locka, North Miami, Little River, parts of Liberty City, east Hialeah, and students from other areas who attend the magnet program.

\section{Description of the Participants}

The participants were divided into three groups: ESOL level 3 (11 students), ESOL level 4 (8 students), and ESOL level 5 (5 students). The level 3 and 4 students all 
shared the same writing class and the level 5 students (the mainstreamed students) were in my other classes. Being an ESOL student in Miami is different though, as many non-ESOL students speak the same language or even come from the same household as an ESOL student. As an example, the older sisters of one of my ESOL level 4 students were not in ESOL and might never have been.

\section{Data Collection}

\section{Introduction}

The data were gathered using a Likert scale designed to gauge the students' opinions on the technology, the roles of their teachers in the writing process, and their receptivity to using the same technology in their other classes. The questionnaire consisted of 19 questions (see below) that asked students for their opinions on a variety of topics in writing. 
Fig. 5.

\section{Student Writing Technology Survey Questionnaire}

\begin{tabular}{|c|c|c|c|c|c|}
\hline \multicolumn{6}{|l|}{ Please respond carefully and honestly } \\
\hline & SD & $\mathrm{D}$ & $\mathrm{N}$ & $\mathrm{A}$ & SA \\
\hline \multicolumn{6}{|l|}{ Using the writing program made me feel more in control of my own writing } \\
\hline \multicolumn{6}{|l|}{ Essay writing stresses me out because it is a difficult task } \\
\hline \multicolumn{6}{|l|}{ Essay writing stresses me out because teachers are too picky } \\
\hline \multicolumn{6}{|l|}{ I could write better essays if teachers did not give me as many corrections } \\
\hline \multicolumn{6}{|l|}{ I use the corrections that the teacher gives me to write my final drafts } \\
\hline \multicolumn{6}{|l|}{ Using the writing program helped me improve my final draft } \\
\hline \multicolumn{6}{|l|}{ Using the writing program gave me less stress than not using it } \\
\hline \multicolumn{6}{|l|}{$\begin{array}{l}\text { Using my first language in the writing process helped me write a better final } \\
\text { draft }\end{array}$} \\
\hline \multicolumn{6}{|l|}{$\begin{array}{l}\text { Other students would benefit from using writing software before handing in a } \\
\text { final draft }\end{array}$} \\
\hline \multicolumn{6}{|l|}{ I like that the teacher speaks the same languages as I do } \\
\hline \multicolumn{6}{|l|}{ Using the writing program made the writing process faster } \\
\hline \multicolumn{6}{|l|}{ Using the writing program improved my writing skills } \\
\hline \multicolumn{6}{|l|}{ I want to use this technology for future writing assignments the same way } \\
\hline \multicolumn{6}{|l|}{ Using this technology improved my understanding of technology } \\
\hline \multicolumn{6}{|l|}{ I feel comfortable letting these programs grade my writing instead of a teacher } \\
\hline \multicolumn{6}{|l|}{ I do not trust most of the corrections my teacher gives me on my writing } \\
\hline \multicolumn{6}{|l|}{ I do not trust the corrections given to me by the writing software } \\
\hline \multicolumn{6}{|l|}{ The technology was useful, but teachers should grade the final draft } \\
\hline The technology was not useful and should not be used in writing classes & & & & & \\
\hline
\end{tabular}


Students were instructed to fill in their survey by marking the table appropriately using the designations "SD" for strongly disagree, "D" for disagree, "N" for neutral, "A" for agree, and "SA" for strongly agree. A five point Likert scale was selected instead of a four point - where a neutral choice would not be offered — because my relationship with my students indicated that the neutral option would most likely lead to more honest answering, thereby reducing the Hawthorne effect (Monahan and Fisher 2010).

\section{Coding the Questionnaire}

Questions 1, 2, 3, 4, and 15 connected to the report by Palacio (2011) and how she noticed the anxiety of her high school students in Miami. Those questions, along with questions 16 and 18, also tie into Aukerman's (2013) idea of "rightness" and how students are being programmed to think in one specific way as well as Sanders-Reio's (2014) descriptions of self-efficacy in writing. Question 18 probed the students to see how they felt about their teacher and the idea of imposed "rightness" through essay grading. Questions 5, 7, 8, and 10 corresponded to the article written by Bean et al (2011) regarding the use of home languages in the writing process. Questions 6, 9, and 11 correlate to the research on feedback and revising activities done by Paulus (1999) and its effects on writing. Questions 12,13, 14, 17, 19 were connected to the research and writing done by Perelman (Kolowich 2014), Shermis (2014), and Warschauer (2007) regarding the use of AES software in general and specifically how it can be used as a tool for students and teachers. Though Perelman and Shermis focused more on its use as a 
final assessor, they still served as a useful template to frame the issue of using AES technology at all as well as the perceptions people might have of it.

Each of the 19 questions also play directly into the two research questions. In the figure below, each of the questions are listed with their corresponding research questions (see fig. 6). 
Fig. 6. Each of the 19 Questions in the "Student Writing Technology Survey"

\begin{tabular}{|c|c|}
\hline Using the writing program made me feel more in control of my own writing & RQ1 \\
\hline Essay writing stresses me out because it is a difficult task & RQ1 \\
\hline Essay writing stresses me out because teachers are too picky & RQ1 and RQ2 \\
\hline I could write better essays if teachers did not give me as many corrections & RQ1 \\
\hline I use the corrections that the teacher gives me to write my final drafts & RQ1 and RQ2 \\
\hline Using the writing program helped me improve my final draft & RQ1 \\
\hline Using the writing program gave me less stress than not using it & RQ1 \\
\hline Using my first language in the writing process helped me write a better final draft & RQ2 \\
\hline Other students would benefit from using writing software before handing in a final draft & RQ1 \\
\hline I like that the teacher speaks the same languages as I do & RQ2 \\
\hline Using the writing program made the writing process faster & RQ1 \\
\hline Using the writing program improved my writing skills & RQ1 \\
\hline I want to use this technology for future writing assignments the same way & RQ1 \\
\hline Using this technology improved my understanding of technology & RQ1 \\
\hline I feel comfortable letting these programs grade my writing instead of a teacher & RQ1 \\
\hline I do not trust most of the corrections my teacher gives me on my writing & RQ2 \\
\hline I do not trust the corrections given to me by the writing software & RQ1 \\
\hline The technology was useful, but teachers should grade the final draft & RQ1 and RQ2 \\
\hline The technology was not useful and should not be used in writing classes & RQ1 \\
\hline
\end{tabular}




\section{Data Analysis}

Once the data were collected, they were analyzed one-by-one to detect general trends in the responses (see fig. 7) of the students and then broken down according to the responses by the students in different ESOL levels. The grouping is important to help predict and account for issues such as misunderstandings of the survey questions, particular aspects of the program that are favored at different stages of ESOL, and overall feelings about writing in school, as some have had more success at it than others. But, As previously mentioned, it would be difficult to assert these findings as evidence that ESOL students of similar levels would respond in different manners. Rather, it could serve to indicate how students with similar linguistic backgrounds, writing skills, and other pertinent demographic information might similarly respond to the same types of questions, thereby allowing for regional and linguistic differences to be factored in when compared to the mostly Haitian backgrounds of the students that participated in the project. For example, Asian immigrant students in Palo Alto would have a completely different experience from Dominican students in New York or Haitian students in Miami.

\section{Ethical Considerations}

The names, educational backgrounds, and other pieces of personal information were not collected for the project. Any student who was not given permission from their parents, did not sign for themselves, or did not complete the essay that was being revised were removed from the project. The focus of the project was determining whether or not the writing scores and self-efficacy of high level ESOL students could improve, not 
necessarily the background of the students. Though part of the project included specific information regarding the fact that some of the students come from homes where Haitian Creole was the primary language, there are over 500,000 people of Haitian descent living in South Florida, making it difficult to determine which high school these students attend. To further ensure their safety and privacy, the name of the school is not mentioned in the research.

As their teacher, I had access to students' records until shortly after the school year ended. Sometime in mid-June, the system resets and teachers do not have access to any student information until they receive their rosters for the next school year. In addition, I used my personal computers (which allowed me to install a protective password on personal information) instead of the easily accessible school computer to record any and all information, thus eliminating the chance that a student, another teacher, or an administrator might stumble upon the information for whatever reason. Once the data were collected and presented in text form, all student information was reduced to basic, difficult to trace markers, such as first language, age of arrival to the United States, and information that was gathered as a group rather than individually.

Though this project took place during regular classroom instruction, students had the choice to opt out of the project if they or their parents felt uncomfortable participating. On the authorization form signed by both parents and students, the ability to choose not to participate was explained along with a guarantee that any student who did not participate would not face reprisal. This document is included in the appendix in English, Haitian Creole, and Spanish (see appendix B). 


\section{Validity}

There were some concerns regarding the validity of the data given the small sample size, the fact that I am their teacher (participant bias), and possible misunderstandings of the questions being asked of them. Therefore, the data compiled from the questionnaire was not seen as hard proof of how students feel about AES, writing, and the use of L1 in writing, but rather as possible trends in those areas that are reflective of the participants and students with similar backgrounds. The data was also compared as indicative of trends rather than hard and fast numbers and was described as such. This allows the opportunity for further study where the data can be compared alongside the varying demographics of students in other schools and communities. Understanding and giving weight to the backgrounds of each ELL student is crucial for understanding their specific educational needs, thus necessitating flexible determinations and increasing the importance of context for the Haitian students involved in the project.

With these caveats in mind, the following concepts have been identified as threats to validity with respect to this project. Following the listing is a brief discussion of how these threats were/were not controlled for in the study:

- Invalid application of the instrument. A typical example would be if a general proficiency test were used as a measure of a specific classroom learning objective. In this study, the 19 item Likert questionnaire was specifically designed to assess students' opinions on the AES technology, the teachers' role in the composing 
process, and the students' receptivity to using the AES technology in their other classes. This threat was controlled.

- Inappropriate selection of content. This occurs when there is a mismatch between the objectives and the items. This is called a Type VI error (Perkins and Newman, 2014). This threat was controlled because the questions were specifically designed to address students' opinions on the AES technology, the teachers' role in the composing process, and the students' receptivity to using the AES technology in their other classes.

- Imperfect cooperation of the subject pool. If the subjects are insincere, misinformed, hostile, or intent on "blowing off the exercise," this can lead to what is known as a lack of response validity. Because the questionnaires and the use of the AES were embedded in the typical instruction, the lack of response validity was controlled for. In fact, this entire exercise could be viewed as authentic assessment because the activities described in the study were based on/derived from instructionally-relevant classroom activities. It is the case that some students may have felt compelled to answer a certain way because I am their teacher, more so than the usual observer effect associated with these types of experiments. This is called the approval motive (Crowne and Marlowe, 1964), which has to do with the tendency to want to appear acceptable in the eyes of others (Oller and Perkins, 1978).

- Sample truncation. Sample truncation can lead to an artificial restriction of the range of endorsement of the questions. There were some students who switched 
out of my class due to typical schedule changes, some transferred to other schools, and a small number did not complete the assignment and had to focus on getting caught up during the experimental window.

- Use of invalid constructs. This occurs when the constructs or hypothesized abilities are not valid to begin with. The constructs are valid: whether AES software could be used as a classroom tool to improve high level ESOL student writing, and students' response to the use of their native language.

- Unclear directions. If students don't know how to respond or how to record their answers, validity can be reduced. To reduce this threat, I explained the questions to the students before they responded to the questionnaire..

- Vocabulary and sentence structure at the inappropriate level. Vocabulary and sentence structure that are too complicated may result in measuring reading comprehension and intelligence. Since the students were of an advanced ESOL proficiency, I used within the oral explanations vocabulary akin to Beck et al (2002) Tier II Level of Academic Vocabulary.

- Inadequate time limits. If students are not given enough time to consider the questions and provide thoughtful responses, validity can be reduced. To control for this type of threat, I gave the students entire class periods (90 minutes) to focus on writing and rewriting their essays. 


\section{Role of the Researcher}

Though I am optimistic of the future possibilities presented by the experiment and the alternative use of the software, it was imperative to not let my instincts dominate and insert my personal biases into the study. Therefore, aside from instructing the students on how to use the program as well as explain the results (without coaching them to see the results in a certain way), I kept my speaking to them to a minimum and allowed them to analyze the results for themselves. For the sake of getting more valid results, I encouraged all of the students to make revisions and send their revised essays back through the program to see if it gave them different results; most of the time, this led to score increases on the 100-point scale of the program, but there were times that the scores would be inexplicably lowered. In these situations, I maintained my neutrality but explained that sometimes the system is not perfect. 


\section{CHAPTER IV}

\section{RESULTS}

This study investigated the use of AES software as a classroom tool for high level ELL students. To do so, high level ESOL students in a high school writing class used AES software in the middle of the writing process as a revision assistant tool. The students then responded to a questionnaire that reported their feelings of self-efficacy and confidence in writing. The following research questions framed the sub-questions of this questionnaire:

1. When using AES software as a tool in the writing process, do high level ELL students report an increase in their sense of self-efficacy as a result of revising of their work?

2. Do high level ELL students report, as a result of writing essay outlines/notes in their home language (especially Haitian Creole), an increase in their feelings of confidence when writing their final drafts in standard English?

The composite results of the questionnaire are shown in figure 6 .

\section{Question 1: When using AES software as a tool in the writing process, do high level} ELL students report an increase in their sense of self-efficacy as a result of revising of their work?

Overall, the students had a positive experience with the use of the software and they, were more confident in their writing abilities than expected. They also generally did 
not feel as if their writing was hindered by the pickiness of their teachers or negatively

impacted by how they

Fig. 7. Questionnaire Response Percentages

\begin{tabular}{|c|c|c|c|c|c|c|}
\hline $\mathrm{n}=\mathbf{2 4}$ & SD & D & $\mathrm{N}$ & A & SA & RQ \\
\hline $\begin{array}{l}\text { Q1: Using the writing program made me feel more in control of my } \\
\text { own writing }\end{array}$ & $0 \%$ & $0 \%$ & $17 \%$ & $50 \%$ & $33 \%$ & 1 \\
\hline Q2: Essay writing stresses me out because it is a difficult task & $13 \%$ & $13 \%$ & $38 \%$ & $17 \%$ & $21 \%$ & 1 \\
\hline Q3: Essay writing stresses me out because teachers are too picky & $29 \%$ & $29 \%$ & $25 \%$ & $17 \%$ & $0 \%$ & $1 \& 2$ \\
\hline $\begin{array}{l}\text { Q4: I could write better essays if teachers did not give me as many } \\
\text { corrections }\end{array}$ & $42 \%$ & $8 \%$ & $25 \%$ & $13 \%$ & $13 \%$ & 1 \\
\hline $\begin{array}{l}\text { Q5: I use the corrections that the teacher gives me to write my final } \\
\text { drafts }\end{array}$ & $0 \%$ & $4 \%$ & $13 \%$ & $42 \%$ & $42 \%$ & $1 \& 2$ \\
\hline Q6: Using the writing program helped me improve my final draft & $0 \%$ & $0 \%$ & $17 \%$ & $29 \%$ & $54 \%$ & 1 \\
\hline Q7: Using the writing program gave me less stress than not using it & $0 \%$ & $0 \%$ & $29 \%$ & $38 \%$ & $33 \%$ & 1 \\
\hline $\begin{array}{l}\text { Q8: Using my first language in the writing process helped me write a } \\
\text { better final draft }\end{array}$ & $13 \%$ & $13 \%$ & $29 \%$ & $42 \%$ & $4 \%$ & 2 \\
\hline $\begin{array}{l}\text { Q9: Other students would benefit from using writing software before handing } \\
\text { in a final draft }\end{array}$ & $4 \%$ & $0 \%$ & $25 \%$ & $25 \%$ & $46 \%$ & 1 \\
\hline Q10: I like that the teacher speaks the same languages as I do & $8 \%$ & $0 \%$ & $8 \%$ & $25 \%$ & $58 \%$ & 2 \\
\hline Q11: Using the writing program made the writing process faster & $0 \%$ & $8 \%$ & $21 \%$ & $42 \%$ & $25 \%$ & 1 \\
\hline Q12: Using the writing program improved my writing skills & $4 \%$ & $4 \%$ & $29 \%$ & $25 \%$ & $38 \%$ & 1 \\
\hline $\begin{array}{l}\text { Q13: I want to use this technology for future writing assignments the } \\
\text { same way }\end{array}$ & $0 \%$ & $0 \%$ & $29 \%$ & $29 \%$ & $42 \%$ & 1 \\
\hline Q14: Using this technology improved my understanding of technology & $0 \%$ & $4 \%$ & $42 \%$ & $29 \%$ & $25 \%$ & 1 \\
\hline $\begin{array}{l}\text { Q15: I feel comfortable letting these programs grade my writing } \\
\text { instead of a teacher }\end{array}$ & $4 \%$ & $13 \%$ & $25 \%$ & $29 \%$ & $25 \%$ & 1 \\
\hline $\begin{array}{l}\text { Q16: I do not trust most of the corrections my teacher gives me on my } \\
\text { writing }\end{array}$ & $25 \%$ & $21 \%$ & $33 \%$ & $17 \%$ & $4 \%$ & 2 \\
\hline $\begin{array}{l}\text { Q17: I do not trust most of the corrections given to me by the writing } \\
\text { software }\end{array}$ & $33 \%$ & $21 \%$ & $29 \%$ & $17 \%$ & $0 \%$ & 1 \\
\hline $\begin{array}{l}\text { Q18: The technology was useful, but teachers should grade the final } \\
\text { draft }\end{array}$ & $8 \%$ & $13 \%$ & $29 \%$ & $21 \%$ & $29 \%$ & $1 \& 2$ \\
\hline $\begin{array}{l}\text { Q19: The technology was not useful and should not be used in writing } \\
\text { classes }\end{array}$ & $46 \%$ & $25 \%$ & $17 \%$ & $8 \%$ & $4 \%$ & 1 \\
\hline
\end{tabular}


grade their written work, though there was not a consensus either. $58 \%$ of the students responded "strongly disagree" or "disagree" to teachers being too picky with grading and $46 \%$ strongly disagreed or disagreed with the statement that they "do not trust their teachers' corrections." This starts to put the issue of this technology squarely back into the consideration stage of implementation in regard to using them as the final grader: students still believe that the feedback of the teacher and their normative assessment behavior are not obstacles in the process of writing. In fact, most of the responses regarding teachers were positive, most responding that they find the teacher feedback valuable in their writing and they their teachers' judgments (questions $3,4,5,16$, and 18). At the same time, the students also responded that they felt that the software was beneficial to their own writing and is something they felt that other classes should consider using as part of the writing process.

Another interesting result came from the questions regarding whether or not the software should be used to grade essays instead of teachers. For question 15, most of the students (54\%) responded that they either 'agree' or 'strongly agree' that computers should handle this responsibility. This could mean several things. The program in particular, paperrater.com, tended to grade the papers on the higher end of their scale. For example, the lowest score I saw was still around $80 \%$ (the $\mathrm{C}+$ to B- range). Students might feel that allowing the computer to grade their essays would permit them multiple opportunities to revise after submission (especially when juxtaposed with the later questions about the role of the teacher as a the grader). It could also mean students were defining 'grading' in the sense of grading the checkpoints (outline, notes, rough draft, 
etc.) as opposed to the final grade for the final draft. It is also possible that they separate writing the essay from skill building and see it solely as a means to an end, especially when it comes to their GPA.

In the data from the questionnaires, several positive patterns emerged. For the ESOL level 3-4 students, the majority of respondents for question five (16/19) and question six (16/19) felt that using this technology in the classroom could improve their essay writing but they also needed input and feedback from their teachers. The ESOL level 5 students were more mixed on this issue and had a stronger negative response to feedback from their teachers. This could be in part due to the idea of 'noticing' put forth by Schmidt (1990), and the more feedback a student gets from a teacher, the more things on the paper are available to be noticed. For the ESOL level 5 students, they might not feel the need to 'notice' as much as they used to. It could also mean that they completely orient themselves as "mainstream" students, not ESOL students. Some of the level 5 students who participated were not aware of their status as ESOL students, thus lending some credibility to this idea. Interestingly, the level 5 group also had the highest positive response rate to the question regarding use of the first language in the writing process. While impossible to verify this, because none of the participants used their L1 in the note taking, rough draft, nor revision of their essays, their response might be explained by internal code-switching while composing or comparing how an idea or phrase sounds in their L1 and L2.

In regard to their response to the software, the level 5 students had a generally positive response with the exception of question 18. The level 3-4 students mostly agreed 
that the software could help other students write better essays, but the level 5 students had mostly neutral or negative responses to the question. The degree of disagreement to the majority of the other participants might be from their responses coming from a smaller pool (five level 5 students vs 19 level 3-4 students). It could also mean, however, that because they are in mainstream classes and the project excluded anyone who was not ESOL, they felt like they were being singled out and that the technology was not meant for 'normal' students.

The level 3-4 students were much more consistent in their responses. If the level 5 students felt awkward for using it while being in a 'mainstream' class, the level 3-4 students did not have the same qualm because they were all in the same class. In contrast to the level 5 students, they both believe that teacher feedback is necessary, the technology helped them improve their writing, and that other students should have the chance to use the software. What they all had in common, though, is the interest to use these programs in their next writing assignment (no 'disagrees' or 'strongly disagrees'). The small number of ESOL level 5 participants made it difficult to put together a clearer picture of what they had in their mind. In future studies, a more balanced ratio of students will help yield more detailed results. 


\section{Question 2: Do high level ELL students report, as a result of writing essay}

outlines/notes in their home language (especially Haitian Creole), an increase in

\section{their feelings of confidence when writing their final drafts in standard English?}

According to the results of the questionnaire, namely questions $3,5,10,16$, and 18 , students do not report an increase in their feelings of confidence when writing with respect to their home language. They do, however, show confidence regardless of language and through their ability to trust in their teacher-no matter who that teacher is.

Though the data sample is not large, there are still salient trends and information that can be gleaned, especially when it comes to the overall positive response to the software. It is important to understand that the students still value their teachers and might not feel as positively about the experience without the guiding presence of their teacher.

Still, the results indicate that it probably helped tremendously that I can connect with students on different levels, including the ability to speak their first language (on question ten, $83 \%$ "agreed" or "strongly agreed" that this is something they enjoyed in a teacher). But ultimately it might not matter that the experiment happened in my classroom. Sophomores at the school have a core English class, a reading class, and a writing class (with mine being one of them). Their positive response probably extends to their other ELA classes, and it might not be a great leap of faith to assume that they had their other classes in mind when they responded the way that they did. 


\section{General Considerations Based on Questionnaire Results}

Due to the small sample size, determining generalizability of the findings was not a part of this study. Of course, it would be feckless to suggest that these findings should be the basis for wide scale change in the teaching of the writing process; it might even be too quick to encourage the school I work at to adopt the format based on the positive response of my students. However, for the students of my classes the results have been impressive enough to continue implementing the software as one step in the writing process. For the most proud of my students, they can subtly make edits and eliminate things spelling errors or heed suggestions to bolster the domain specific vocabulary of their work; for the collaborative minded student, they might share the feedback given to them by the program and ask for my input in order to plot out their next steps for revising and rewriting. I also trust the students, making it easier for everyone in the classroom to communicate and to be honest regarding their opinions on the software.

One of the potential problems was the possibility of some of the students not fully understanding what was being asked of them in the questionnaire (especially some of the ESOL level 3 students). There were a few instances of students' probable misunderstanding, such as responding positively to "the software should be used in the classroom" as well as "the software should not be used in the classroom" (the last two questions on the questionnaire). The other major issue was the small sample size, especially with the ESOL level 5 students. There were some students who switched out of my class due to typical schedule changes, some transferred to other schools, and a small number did not complete the assignment and had to focus on getting caught up 
during the experimental window (one week) instead of fully participating. They were given the chance to use the software as well but were not given the chance to respond to the questionnaire. Another issue was the fact that they might have felt compelled to answer a certain way because I am their teacher, more so than the usual observer effect associated with these types of experiments: they might have had fear of reprisal were they to answer with anything except that they love my ideas, conceptual framework, and writing itself. I would hope this is not the case, but if it would probably help to have less of a direct hand in their day to day lives were this experiment were to be done again. Interestingly, when the students were given the chance to take notes and compose in their native languages, none of them took the opportunity. This made their response to the question regarding their use of their first language interesting, as most of them had neutral to positive feelings to including it in the writing process. It is possible that that for them it was an internal process that occurred within their minds. Though their abstention from using their first language in the process made the question somewhat irrelevant to the specific goals of the experiment, it does open up for interesting research topics/questions regarding the mental processes of ELL students as they write in English. It is also possible that for them, being able to ask me questions in another language prompted their response; it is also possible that they wanted to use their first languages but were unsure of how to write in it (especially for Haitian students). 


\section{Delimitations of the Study}

The conducting of this study was hampered by the fact that the writing department at the school received a mandated lesson calendar that constrained the pedagogical freedom necessary to design an experimental study that included pre and post analyses using this questionnaire. The focus then instead was the revision process for a grade level essay and using the software program as one step in that process. Also, students who frequently missed class were not allowed to participate in the study because they would not have enough time to plan, type, use the technology, then submit the essay. From all of the students eligible for inclusion, around 5-10 were not allowed to participate due to one of those conditions being met or due to a school transfer.

The original plan for the project was for the control students to go through a traditional lesson plan using traditional strategies and grading. Then, for the second data collection, students would then have used an AES software program to analyze their essays and provide them feedback. Students would review the feedback and determine which aspects of it they agree with and which aspects they disagree with. After, they would have made revisions on their essay based on the feedback and then submit it to me for a final grade based on the same state rubric.

However, due to a shift in the instructional calendar originating in the district office, this plan had to be altered. For this project, there was not a traditional control or experimental group. Rather, students were all put into a research subject group. The data used for analysis was collected from a questionnaire (attached later on and in the appendix). In the future, I would like to lead a true experiment where there are traditional 
control/experimental groups, but for this project my job security forced me to make changes. 


\section{CHAPTER V}

\section{CONCLUSION}

This project examined AES, high level ELLs in a high school writing class, and issues of linguistic bases, especially for Haitian Creole speaking students. This chapter then details the academic implications of this project as well as personal reflections upon the project. These personal reflections, posed concurrently with the questionnaire results, seem part of the overall story cast by my school and my students. The quantitative approach to Likert scale analysis is therefore discussed in this chapter along with personal narrative in the qualitative sense as supported by Barkhuizen (2011).

\section{Review}

The project was successful in terms of investigating AES software as a revision assistant, learning more about the role of the L1 (especially Haitian Creole) in a writing class, and setting the foundations for further study. Many students in the U.S. do not have teachers who speak the same language as they do or can connect with them in deep, meaningful ways. These realities can make things such as Krashen's theory of the affective filter difficult for some schools to harness, as those differences can be the foundation for separation rather than integration. What the computer programs can do in this sense is help the students improve their writing and help the teachers help their students improve their writing through the means of a third party. The students, with their sense of trust in the software indicated by their responses, could get more revising done 
(with the teacher, too) and restructure the writing process to be more recursive. Instead of writing, getting notes from the teacher on the rough draft, then submitting it again and hoping for a better grade, students would send their work through several cycles of the AES in order to fine tune it and strengthen their own work. Some teachers fear that these programs will put them out of a job, but as the students who participated in this study pointed out, many high school students would still prefer to have their teachers grade their final drafts.

Though this project initially set out to explore issues of self-efficacy in writing and how AES software could possibly increase it in ESOL students, outside forces shifted the focus onto generally how students responded to the technology in the classroom. There were observable differences in self-efficacy (see fig. 7), but another experiment will be necessary to measure those differences. The results of this project showed that students are amenable to using these programs in the classroom alongside the guidance of a teacher; this can make the process of measuring their revisions and devising the instruments to do so easier. Other future extensions of this project could include other technology, such as eye tracking machines, keystroke recorders, voice recording technology (especially for recording ideas for later use in their L1), and writing lab type programs (which include vocabulary notes, grammar exercises, thesaurus and dictionary, etc.). While the debate as to whether or not this technology should be used to grade high stakes testing rages on, these students showed that using them in a different way now could help them develop as writers immediately. 


\section{Summary}

With the implementation of the Common Core and its emphasis on writing, new steps should be taken to better understand the different factors that play into writing, especially for ELL students and students who speak dialectal forms of English at home. This project investigated how ESOL students responded to AES technology when it is used in the middle of the writing process instead of the final step, thus giving them more tools at their disposal as well as give them more opportunities to review their work. Also, an attempt was made to manipulate the affective filter as a means to increase the confidence and, hopefully, the self-efficacy of the students in this project. This was attempted by allowing them to use their home languages as part of the first steps of the writing process, such as their notes, outlines, and discussions (Bean 2011). Haitian Creole speaking students might doubly benefit from being able to use Haitian Creole in a regular US classroom because not only will they be able to better connect with their writing skills overall by developing their first language skills (Cummins 2001), but the language has been maligned and misunderstood in Haiti and the United States. Finally, this project hoped to serve as a model for future studies regarding the use of current AES software to help students revise rather than to have their writing assessed.

AES software will undoubtedly have a seat at the table in future conversations regarding policy, testing and assessment, and the role of technology in the modern classroom. What was made evident to me by writing and undertaking this project was that students who speak languages other than English at home still believe they need the assistance of their teacher to continue developing and eventually mastering academic 
English. When AES is used in the middle of the process, however, these same students were given additional opportunities to revise their written work, bring their teacher into their thought process via neutral third party (the AES program used in the project), and notice much more about writing (questions $6,7,13,17$ from the questionnaire) and how to improve it similar to the way Richard Schmidt "noticed" Portuguese. Despite the promise of this technology as a classroom tool in the aforementioned ways and others (increasing the amount of writing, increasing the speed and efficiency of the writing process, etc.), there are still major hurdles that need to be conquered and serious consideration into who and what are going into the classrooms and designing the algorithms to assess the student essays.

As the technology stands right now, some programs favor longer sentences, technical language (sometimes needlessly so), and use "brute force" (Ben-Simon 2007) programming that focus on topical linguistic features. This creates its own set of problems, as a concisely written but brilliant piece of rhetoric might be crushed under the weight of the computer and the algorithm. For ESOL students and students who speak any of the dialectal varieties of English at home that were mentioned throughout, they might be disproportionately adversely affected by the results of an AES program. Most of the programmers, coders, and other professionals creating and distributing the software are white non-Hispanic from high socioeconomic backgrounds. What's troubling is that when some of the superfluous jargon is included and factored in to the assessment of student essays, students from a background with features typical of high SES (college educated parents and communities, more communication at home, increased likelihood of 
white collar jobs or professional careers) might be more privy to the type of "whitestream" language the software is being programmed to detect. A great example of this was described in the New York Times in by Sword (2012), a professor at the University of Auckland. She described the phenomenon of nominalizations (or "zombie nouns" as she put it) and how they water down our writing as well as come across as a way to sound "pompous and abstract." Whether or not the language she describes is dead or not, the reality is that students from different linguistic backgrounds would not have the same access to this type of language as would the children of college educated parents. And despite the separate set of problems created by nominalizations in modern English, the reality is that coming from a high schooler or middle schooler, it could easily come across as talent rather than smoke and mirrors. Many minority and low SES (socioeconomic) students do not have access to the same "talent" that the AES would appreciate, thus complicating the issue of their use in classrooms as minority children are becoming the majority in US classrooms.

\section{Discussion and Potential Future Experimental Framework}

In order to fully understand not just how students feel about AES but how it changes their writing, more traditional experiments need to be undertaken with control groups and experimental groups. While this project showed that high school students in Miami are amenable to its use, more experimentation needs to take place that establishes that this technology is a bona fide tool to help improve student writing. Until more of those experiments have been conducted and until some of the possible discriminatory 
programming has been addressed, it might suffice to say that AES should not be implemented for widespread assessment as the be all end all it's being touted as. The next figure is a basic chart illustrating a possible experimental scenario.

Fig. 8. Chart for Possible Experiment With AES Software

\section{Control School or Student Group}

\section{Experimental School or Student Group}
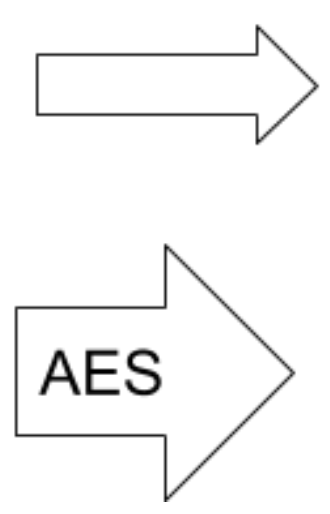

Common Core Writing Rubric
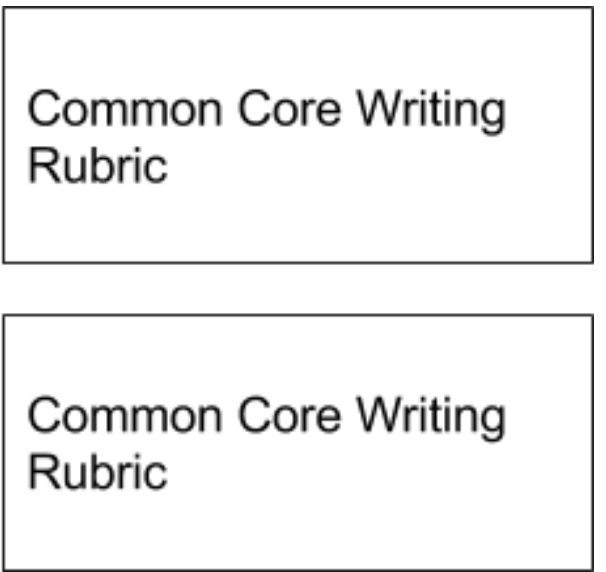

The students were working with the technology that will, plausibly, be the same technology which will be used to grade the essay writing of future generations. Much of the debate surrounding automated essay scoring software has ignored the voices of the students, especially those with stigmatized designations such as "ESOL." Even if the project does not show evidence of possible, positive alternative uses for AES software and its other iterations, they will still be improving their likelihood of passing the writing portion of the new Florida state tests by adding a wrinkle to their pre-prescribed writing class, not to mention be one of the few classes in Miami (and possibly bigger than that) to work with AES in the classroom instead of as part of a standardized test. That all being said, the most notable benefits are the possibilities to receive feedback quickly and privately away from teacher perceptions and grades, feel more confident and empowered 
as they try to pass the necessary tests that restrict them to ESOL, and begin to see the revision process as more about rhetorical constructions rather than a word changing activity.

The same possible benefits could be investigated in other demographic groups to determine if there are broader implications outside of ESOL students. For example, students with complex linguistic histories in the U.S., such as African-Americans and Jewish-Americans, could be recruited to see if the using AES technology in the middle of the process rather than the final assessor could improve their own feelings of agency and efficacy, as well as improve their writing based on standardized rubrics.

Despite some of the lingering issues with AES, especially when it comes to gaming the system, the software is on track to become used as the main grader of writing for high stakes testing. Many programs can be tricked into giving a good grade because they look at the surface levels of writing (vocabulary, grammar, variety, and other basic writing features), not the deeper meanings of the words being used. But, by using that same feedback in the middle of the process instead of the end, students might be able to make more impacting revisions on their final writing drafts.

This project also looked at the possibility of increasing the feelings of self-confidence and control over writing needed to be successful. That feeling when discussing literacy and writing is often referred to as efficacy, and because this project encourages students to take more control and to make decisions on their own writing, it could be called self-efficacy. Students are often paranoid of teacher marks and notes on their writing for many reasons, but fear of getting a bad grade and feelings that the 
teacher does not understand what they are trying to say are consistent notions given by students. By giving what is, according to the makers of AES software, supposed to be feedback based on teacher grading patterns, the goal is to see if using the feedback privately to construct their final drafts can help them make improvements in their writing based on the state writing rubric but also increase their self-efficacy in their writing.

The students involved were not required to do anything not already being asked to do according to the Suggested Implementation Guide (the Miami-Dade County Public Schools' pacing guide). The activity also used technology available to them at school and did not require additional technology or equipment in order to conduct the project. 


\section{EPILOGUE}

\section{Reaction}

Schools are going down the path of becoming test-passing factories, and one of the prevailing philosophies of classroom management is a response to that reality: students are being expected to sit down and shut up. This reality creates students who might be fearful, sad, and on the wrong side of affective filtering. When technology is implemented in that type of educational environment, students might be reluctant to speak up or ask questions in order to learn.

Another related problem with students' use of technology appears when they either lack a computer at home or their family has a computer with limited functionality. It is not uncommon for students at high schools across Miami (including the one I work at) to fail to complete essays and other writing assignments due to the simple fact they do not have access to a computer at home. Some teachers try to "fix" this by telling them to take public transportation to get to the library, but for female students particularly the city bus is not a safe option for them at night. The other issue is the relative lack of supervision when they use technology at home. Though not every teacher is computer savvy, teachers must have basic knowledge of how to operate a computer and how to write on one given the common use of technology by school districts as a means of communication. This basic knowledge can be imparted from teacher to student to serve as both the foundation for the abstract comprehension of computers as well as the linguistic basis for that comprehension. 
Also, just as teachers need to be aware of the dynamics involved in teaching writing to students from different backgrounds, teachers and tutors (especially in Miami) need to be aware of who can be of extra assistance in terms of 'reaching' students and their writing. Establishing a peer tutoring program or one similar to the program described by Palacio can free up time for teachers to make stronger plans, do their own research on the different cultures their students come from, and to help students in their writing even more with people who are more closely related in age and background. However, tutoring programs might not always be the most practical approach because of simple logistics: not every high school will share a fence with a university and not every high school will be allowed to have such a program due to bureaucratic red tape. The benefits however were noticeable and the city of Miami would definitely have the manpower (there are plenty of college educated or college students in Miami who would be willing to participate in a structure program) available to help every high school student in Miami. Students who receive such help might not only expand their writing abilities, but their literacy as well in the sense of being exposed to spoken formal academic terminology in a way that they can relate to, given the similar backgrounds of the tutors and the students. Introducing a computer into that equation would only open up more literacy functions given the technical language of both the software and the hardware.

\section{Fieldnotes}

The concept of the writing process not only encapsulates those ideas and gives students an effective strategy, but it also pushes them to go back to a step before 
submitting their final draft. For example, whenever a student finishes an essay suspiciously fast, I ask them if what they are about to turn in is the same level of writing as what they would compose for their state writing assessment. If they say yes, then I'll look it over and usually push them back to one stage of the process. Technology has the potential to not only hasten this process but to create more opportunities for revising and editing by giving the students more opportunities to improve their essays before handing them in to the teacher for a grade. This also allows the teachers to collaborate with the students on their writing while using the AES as a mediator. The students will get feedback from the software and edit their work on their own and with the teacher instead of handing in their paper for a grade. By adding an extra layer to the writing process and the revision process in particular, the students can spend more time and energy on revising and fine-tuning their ideas instead of getting stuck at earlier stages of the process. The teacher can facilitate this as well by encouraging the students to put down their ideas without worrying about immediately getting a low score on their essays due to the extra time spent on writing and rewriting.

\section{Environment and Accountability}

At "high accountability"1 schools in Miami, school district personnel will often come in and mandate that different departments change everything they are doing. For example, during my first year as an "interventionist", a recently promoted district

${ }^{1} 1$ High accountability schools refer to schools that have not been seen as successful institutions, whether it be due to low graduation rates or low test scores. In Miami-Dade County Public Schools, the highest accountability schools are overseen by a district office called the "Education Transformation Office" and receive extra support, directives, and mandates from the district (hence the "accountability"). 
employee told the teacher to completely change the way she had had the students write their introductory paragraphs a month or two before the test. And this year at the school I worked at as a full time writing teacher, the other writing teachers were making the district personnel and the literacy coaches nervous about how their students were going to perform on the state writing test. This prompted a complete and total overhaul of the entire writing department and the curriculum.

Despite my love for the students and the school, it must be noted that this specific senior high school was a tough environment to conduct this type of work given the "high accountability" nature of the school. In the middle of the data gathering process, the writing department had the clamps put down on it due to inconsistencies among the different writing teachers. Though the initial idea for this thesis was to have a traditional pre- and post-test, the structure had to be altered to become more like a pilot project, with the focusing shifting from demonstrable differences to focusing on the students' interactions and opinions on the software. Unfortunately, this would mean that having the students more actively comparing a typical writing process in school with a new model of writing all within the same class with the same teacher would have to be done for a different project. Despite the issues, however, the original research questions and most of the original conceptual framework were left intact.

The real modification was the omission of the pre- and post- which measured the differences in writing scores based on the FSA Writing Rubric. This is potentially for the better, as it would have been difficult to measure what differences were due to regular class instruction, reinforcement of skills and techniques in reading and English classes, 
and what was due to the proverbial light turning on independent of the AES software.

The new format of the project instead honed in on the students' responses to the software as well as the potential the software showed in helping students do more revising in their writing.

Despite the idea of "high accountability", students lost weeks of instructional time due to state testing. In the minds of the students and some of the teachers, classes were essentially finished after the test: students and teachers telling each other that they "aren't doing any work after the test" was a common refrain towards the end of the school year. And when other classes had their test coming up, entire class formats were subject to alteration in an attempt to give the students as much time to prepare as possible. For example, at a high school in Miami, the literacy coach made the junior English teachers stop everything they were doing and made them present PowerPoint presentations about U.S. History. This was done in order to give them more practice and information for the US History end of course exam. For as long as we allow tests to be the focus of public education, there will not be a force pushing us back to what the real focus of education is supposed to be: the students. 


\section{BIBLIOGRPAHY}

Aukerman, M. "When Reading It Wrong Is Getting It Right: Shared Evaluation Pedagogy among Struggling Fifth Grade Readers." Research in the Teaching of English, 42.1 (2007):56-103.

Aukerman, M. "Rereading Comprehension Pedagogies: Toward a Dialogic Teaching Ethic that Honors Student Sensemaking." Dialogic Pedagogy: An International Online Journal Dialogic Pedagogy. 1 (2013).

Barkhuizen, G. "Narrative Knowledging in TESOL.” TESOL Quarterly 45.3 (2011): $391-414$

Bean, J. et al. "Should we invite students to write in home languages? Complicating the yes/no debate." Second-language writing in the composition classroom: A critical sourcebook. Boston: Bedford/St. Martins, 2011.

Beck, Isabel L.; McKeown, Margaret G.; and Kucan, Linda. (2002). "Choosing Words to Teach.” Reading Rockets. Retrieved July 20, 2016 from http://www.readingrockets.org/article/40304/.

Ben-Simon, A. \& Bennett, R.E. (2007). “Toward More Substantively Meaningful Automated Essay Scoring." Journal of Technology, Learning, and Assessment, 6.1 (2007).

Blood, I. (2011).” Automated Essay Scoring: A Literature Review.” Apple Award Winning Papers In TESOL \& AL. 11.2 (2011).

Blume, H. "L.A. Unified unprepared for computerized state test." Los Angeles Times 2014. Retreived July 20th, 2016 from http://articles.latimes.com/2014/jan/27/local/la-me-lausd-computers-20140128.

Bogdan, R.C. and Knopp Biklen, S. Qualitative Research for Education: An Introduction to Theories and Methods. Boston: Pearson, 2007

Bonenfant, J. L. "History of Haitian Creole: From Pidgin to Lingua Franca and English Influence on the Language." Review of Higher Education and Self-Learning, 4.11 (2011): 27-34.

Bruning, R., Dempsey, M., Kauffman, D. F., McKim, C., \& Zumbrunn, S. "Examining dimensions of self-efficacy for writing." Journal of Educational Psychology. 105.1 (2013): 25-38.

Carrió-Pastor, M. L., \& Mestre, E. M. "Motivation in Second Language Acquisition." Procedia - Social and Behavioral Sciences, 116 (2014): 240-244. 
Cerat, M. L. "The Haitian language: Defying odds and opening possibilities." International Journal of the Sociology of Language, 233 (2015): 97-118.

Chang, D. "Little Haiti residents, businesses say developers pricing them out of neighborhood." The Miami Herald, 2015. Retrieved July 20th, 2016 from http://www.miamiherald.com/news/local/community/miami-dade/article4783545 $\underline{0 . h t m l}$.

Charya, N.; Doshi K.; Bawkar, S; Shankarmani, R. "Intrinsic Plagiarism Detection in Digital Data." International Journal of Innovative and Emerging Research in Engineering, 2.3 (2015): 23-30.

Cho, H. “What Writing Tasks Do TESOL Professors Require?” TESOL Journal 5 (2014): 247-264.

Christensen, L. "The Politics of Correction: How We Can Nurture Students in Their Writing and Help Them Learn the Language of Power." The Quarterly 25.4 (2003): 6-9

Cochran-Smith, M. \& Lytle, S. "Research on Teaching and Teacher Research: The Issues That Divide.” Educational Researcher. 19.2 (1990): 2-11.

Corcoran, C. A. "Fifth Grade Students' Perceptions Of Reading Motivation Techniques." Reading Improvement, 46.3 (2009): 137-142. Retrieved from http://search.proquest.com/openview/417043a493df2d61c6e2db7393ef2172/1?pq -origsite $=$ gscholar

Crowne, D. P. \& Marlowe, D. The approval motive. New York: Wiley, 1964

Cummins, J. "Bilingual Children's Mother Tongue: Why Is It Important for Education?" Sprogforum, 7.19 (2001): 15-20. Retrieved February, 2016, from https://www.homeworkmarket.com/sites/default/files/q2/02/04/bilingual_children s_mother_tongue.pdf.

Curcic, S., Wolbers, K. A., Juzwik, M. M. and Pu, J. "Second Language Writing: Theorizing in Instructional Research P-12.” TESOL Quarterly, 46 (2012): $820-831$.

Dahl, R. The Wonderful Story of Henry Sugar and Six More. New York: Puffin, 1945

Degraff, M. "Linguists' most dangerous myth: The fallacy of Creole Exceptionalism." Lang. Soc. Language in Society, 34.04 (2005). 
Degraff, M. "Language barrier in Haiti." The Boston Globe 2010. Retrieved July 20th, 2016 from

http://archive.boston.com/bostonglobe/editorial opinion/oped/articles/2010/06/16 language barrier in haiti/.

Dejean, Y. "An overview of the language situation in Haiti." International Journal of the Sociology of Language, (1993): 102.

Ebersviller, J. R. Peer Evaluation as an Effective Tool to Improve Twelfth-Grade Students' Writing. Mankato, MN: Cornerstone, 2013.

Ebonics Site (n.d.). Language or Slang? Retrieved July 20th, 2016 from https://sites.google.com/site/ebonicssite/language-or-slang-.

Fels, D., \& Rafoth, B. (2011). "The Promise of Change with One-to-One Instruction." The successful high school writing center: Building the best program with your students. New York: Teachers College Press, 2011. 7-19

Ferguson, C. A. "Diglossia." WORD, 15.2 (1959): 325-340.

Florida Department of Education. Retrofitted Statewide Assessment Scores, 2016. Retrieved July 18th, 2016 from http://www.fldoe.org/accountability/assessments/k-12-student-assessment/historyof-fls-statewide-assessment/fcat-2-0/retrofitted-statewide-assessment-score/2015. $\underline{\text { stml }}$

Florida Standards Assessment. English Language Arts Text-based Writing Rubrics Grades 6-10: Argumentation, 2014. Retrieved July 18, 2016 from http://www.fsassessments.org/wp-content/uploads/2014/07/ArgumentationRubric 6-10 Final.pdf.

Gee, J. "Literacy, Discourse, and Linguistics: Introduction.” The Journal of Education. 171.1 (1989): 5-17.

Gillies, R. M. "The effects of cooperative learning on junior high school students during" small group learning. Learning and Instruction. 14.2 (2004): 197-213.

Ghazvini, S. D., \& Khajehpour, M. "Attitudes and Motivation in learning English as Second Language in high school students." Procedia - Social and Behavioral Sciences. 15 (2011): 1209-1213.

Grant, A. "Review: Arthur K. Spears and Carole M. Berotte Joseph: The Haitian Creole Language: History, Structure, Use and Education.” Applied Linguistics 32.3 (2011): 353-355 
Gronlund, N. E., \& Linn, R. E. Measurement and evaluation in teaching. $6^{\text {th }}$ ed. New York: Macmillan Publishing Company, 1990.

Gunn, C. "Essential Components of Writing Assessments. Presentation at the Montana OPI Assessment Conference 4/28/08." Retrieved July 19th, 2016 from http://www.opi.mt.gov/pdf/Assessment/Archive/Conference/Presentations/08Esse ntialComponents WritingAssess.pdf.

Henning, G. H. (1987). A guide to language testing. Development, evaluation, research. Cambridge: Newbury House Publishers, 1987.

Hult, C. "The computer and the inexperienced writer." Computers in the composition classroom: A critical sourcebook. Boston: Bedford/St. Martins, 2008.

HumanReaders.org. Professionals Against Machine Scoring Of Student Essays In High-Stakes Assessment. Retrieved from http://humanreaders.org/petition/results.php.

Kırmız1, Ö, \& Kırmız1, G. “An Investigation of L2 Learners’ Writing Self-Efficacy, Writing Anxiety and Its Causes at Higher Education in Turkey." IJHE International Journal of Higher Education. 4.2 (2015): 57-66

Kolowich, S. "Writing Instructor, Skeptical of Automated Grading, Pits Machine vs. Machine." The Chronicle of Higher Education. LX(33) (2014, May 2):A12.

Krashen, S. D. Principles and practice in second language acquisition. Oxford: Pergamon, 1982

Lefebvre, C. "Relexification in Creole Genesis Revisited: the Case of Haitian Creole." Substrata Versus Universals in Creole Genesis. Ed. P. Muysken and N. Smith. Amsterdam: John Benjamins Publishing Company, 1986. 279-300.

Lefebvre, C. Creole Genesis and the Acquisition of Grammar: The Case of Haitian Creole. Cambridge: Cambridge University Press, 2006

Leung, C. (n.d.). Automated writing instructional tool for English language learners: A case study of MY Access. Retrieved July 20th, 2016 from https://mc.manuscriptcentral.com/hlaq.

Lippincott, D. and Fuentes-Anderson, B. Automated Writing Evaluation: When is it right for your students? Presentation from TESOL 2015 International Convention and English Language Expo, 2015.

Lodge, R.A. French: From Dialect to Standard. London: Routledge, 1993. 
Mascle, D. "Writing Self-Efficacy and Written Communication Skills." Business

Communication Quarterly. 76.2 (2013): 216-225.

Matsuda, P. "Individualism, academic writing, and ESL writers." Second-language writing in the composition classroom: A critical sourcebook. Boston: Bedford/St. Martins, 2011.

Matsuda, P., \& Silva, T. "Cross-cultural composition: Mediated integration of U.S. and international students." Second-language writing in the composition classroom: A critical sourcebook. Boston: Bedford/St. Martins, 2011.

Monahan, R. "What Happens When Kids Don't Have Internet at Home?" The Atlantic, 2014. Retrieved July 20th, 2016 from http://www.theatlantic.com/education/archive/2014/12/what-happens-when-kidsdont-have-internet-at-home/383680/.

Monahan, Torin; Fisher, Jill A. . "Benefits of 'Observer Effects': Lessons from the Field." U.S. National Library of Medicine, National Institutes of Health, June 1, 2010.

Mulqueen, K. "The idea of a high school writing center." The successful high school writing center: Building the best program with your students. New York:

Teachers College Press, 2011.

O'Connor, J. "New Florida Writing Test Will Use Computers To Grade Student Essays." StateImpact, 2014. Retrieved July 19th, 2016 from

https://stateimpact.npr.org/florida/2014/03/21/new-florida-writing-test-will-use-co mputers-to-grade-student-essays/.

Ovando, C. J.; Collier, V.P. Bilingual and ESL Classrooms: Teaching in Multicultural Contexts. Boston: McGraw Hill, 1998

Paper Rater. Home, 2016. Retrieved July 18, 2016 from http:/www.paperrater.com.

Perry, D. "Communication Breakdown: Haiti's Official Language is Hardly Spoken" The Associated Press. Retrieved July 20th, 2016 from http://faculty.webster.edu/corbetre/haiti-archive/msg02523.html.

Plimpton, G. "Ernest Hemingway, The Art of Fiction No. 21." The Paris Review, Spring. 18 (1958)

Postal, L. "FSA testing: Nearly 15\% of students reported computer problems in 2015." The Orlando Sentinel, 2016. Reteived July 20th, 2016 from http://www.orlandosentinel.com/features/education/school-zone/os-fsa-computertesting-students-problems-survey-story.html. 
Oller, J. W., Jr., \& Perkins, K. Language in education: Testing the tests. Rowley, MA: Newbury House Publishers, Inc., 1978.

Organisation Internationale de la Francophonie. 2014 La langue française dans le monde. Paris: Nathan, 2014.

Palacio, K. "Changes I can see: A high school English teacher's perspective of the writing center's impact on bilingual, Hispanic students." The successful high school writing center: Building the best program with your students. New York: Teachers College Press, 2011.

Paulus, T. M. "The effect of peer and teacher feedback on student writing." Journal of Second Language Writing. 8.3 (1999): 265-289.

Pennington, M. "The impact of the computer in second-language writing." Second-language writing in the composition classroom: A critical sourcebook. Boston: Bedford/St. Martins, 2011.

Perelman, L. "Critique of Mark D. Shermis \& Ben Hamner, Contrasting State-of-the-Art Automated Scoring of Essays: Analysis." The Journal of Writing Assessment 6.1 (2013)

Perkins, K., \& Newman, I. "How multiple regression models can be written to better reflect the complexity of first and second language acquisition research: An attempt to limit Type VI Error.” Multiple Linear Regression Viewpoints. 40 (2014): 41-51.

Prat-Sala, M., \& Redford, P. "Writing essays: Does self-efficacy matter? The relationship between self-efficacy in reading and in writing and undergraduate students' performance in essay writing." Educational Psychology. 32.1 (2012): 9-20.

Reid, J. "Eye" learners and "ear" learners: Identifying the language needs of international student and U.S. resident writers." Second-language writing in the composition classroom: A critical sourcebook. Boston: Bedford/St. Martins, 2011.

Rist, R."Student Social Class and Teacher Expectations: The Self-Fulfilling Prophecy in Ghetto Education." Harvard Educational Review. 40.3 (1970): 411-451

Roca, F. J. The relationship between Salvadoran immigrant students and their teachers (Order No. 3559204). Available from ProQuest Dissertations \& Theses A\&I; ProQuest Dissertations \& Theses Global, 2013 
Rubin, D., \& Williams-James, M. "The impact of writer nationality on mainstream teachers' judgments of composition quality." Second-language writing in the composition classroom: A critical sourcebook. Boston: Bedford/St. Martins, 2011

Ruecker, T., Shapiro, S., Johnson, E. N. and Tardy, C. M. "Exploring the Linguistic and Institutional Contexts of Writing Instruction in TESOL." TESOL Quarterly. 48.2 (2014): 401-412.

Sanders-Reio, J., Alexander, P., Reio, T., \& Newman, I. "Do students' beliefs about writing relate to their writing self-efficacy, apprehension, and performance?" Learning and Instruction. 33 (2014): 1-11

Schmidt, R. W. "The Role of Consciousness in Second Language Learning." Applied Linguistics. 11.2 (1990): 129-158.

http://www.geekwire.com/2013/spellcheck-steroids-city-seattle-implementing-wo rdrake-editing-software/.

Schmidt, R., \& Frota, S. "Developing basic conversational ability in a second language: A case study of an adult learner of Portuguese." Talking to learn: Conversation in second language acquisition Ed. R. R. Day. Rowley, MA: Newbury House, 1986. 237-326.

Seow, A. "The Writing Process and Process Writing" Methodology in language teaching: An anthology of current practice Ed. J. C. Richards. New York: Cambridge University Press, 2002.

Shermis, M. "State-of-the-art automated essay scoring: Competition, results, and future directions from a United States demonstration." Assessing Writing. 20 (2014): 53-76.

Shermis, M., \& Hamner, B. "Contrasting State-of-the-Art Automated Scoring of Essays." 2012. Retrieved July 20th, 2016 from https://www.scoreright.org/NCME 2012 Paper3 29 12.pdf.

Singler, J.V. "Theories of Creole Genesis, Sociohistorical Considerations, and the Evaluation of Evidence: The Case of Haitian Creole and the Relexification Hypothesis.” Journal of Pidgin and Creole Languages 11.2 (1996): 185-230.

Soper, T. "Spellcheck on steroids: City of Seattle implementing WordRake editing software." GeekWire, January 23, 2013. Retrieved July 19th, 2016 from

Spears, A. "Introduction: The Haitian Creole Language" The Haitian Creole Language. Ed. Spears and Joseph. Lanham, MD : Lexington Books/Rowman and Littlefield, 2010. 1-20. 
Stine, L. "The best of both worlds: Teaching basic writers in class and online." Computers in the composition classroom: A critical sourcebook. Boston: Bedford/St. Martins, 2008.

Suárez Büdenbender E. Perceptions of Dominican Spanish and Dominican Self-perception in the Puerto Rican Diaspora. Dissertation. Pennsylvania State University, 2009.

Sword, H. “Zombie Nouns.” New York Times (2012). Retrieved from http://opinionator.blogs.nytimes.com/2012/07/23/zombie-nouns/? r=0

Turnitin.com (2016). Revision Assistant. Retrieved July 18th, 2016 from http://turnitin.com/en us/what-we-offer/revision-assistant.

Valdman, A. "Creole: The National Language of Haiti." Footsteps 2.4 (2000): 36-39

Vanderkooy, P. N. Life pathways of haitian-american young adults in south florida. 2011. Available from Dissertations \& Theses@ Florida International University FCLA; ProQuest Dissertations \& Theses A\&I; ProQuest Dissertations \& Theses Global. (888029378).

Veiga, C. "An inside look at the rocky start to Florida's standardized school test." The Miami Herald, 2015

Velasco, P., \& García, O. "Translanguaging and the Writing of Bilingual Learners." Bilingual Research Journal. 37.1 (2014): 6-23.

Walcott, D. Omeros. New York: Farrar, Straus and Giroux, 1990. 21

Walsh, C. Enabling Academic Success for Secondary Students with Limited Formal Schooling: A Study of the Haitian Literacy Program at Hyde Park High School in Boston, 1999. Retrieved February, 2016, from http://eric.ed.gov/?id=ED446174

Ware, P. D. \& Warschauer, M."Electronic feedback and second language writing." Contexts and Issues Feedback in Second Language Writing. Ed. M., Hyland, K., \& Hyland, F. Cambridge: Cambridge University Press, 2006. 105-122.

Warschauer, M. "Automated Essay Scoring in the Classroom." Paper Presented at the American Educational Research Association, 2006. Retrieved November 21, 2015, from http://www.education.uci.edu/person/warschauer_m/docs/aera-2006-aes.pdf

Wells, J. "Integrating reading into the high school writing center." The successful high school writing center: Building the best program with your students. New York: Teachers College Press, 2011. 
Wong, A. “In 2014, One Size Didn’t Fit All.” The Atlantic. December 23, 2014. Retrieved July 20th, 2016 from

http://www.theatlantic.com/education/archive/2014/12/in-2014-one-size-didnt-fit$\underline{\text { all/384001/. }}$.

Zéphir, F. "Challenges and opportunities for Haitian Creole in the educational system of post-earthquake Haiti." International Journal of the Sociology of Language. 233 (2015):119:13 


\section{APPENDIX A}

\section{IRB Information}

\section{Protocol Information}

\section{Reference \#}

Protocol \#

Protocol Type:

PI:

104175

Original

Dwyer, Eric Approval Date:

Submittal Date: Effective Date:

\section{Author:}

Status:

Inactive Date:

\section{Renewal Date:}

\section{INSTRUCTIONS 1}

\section{Completing this IRB Exemption Form}

This IRB Exemption Form is used for obtaining approval for exempt human subject research. While filling out this form, some questions may have additional information in the blue "?" help icon located on the right of the question. For additional assistance with completing this form, visit the Office of Research Integrity Topaz website located at: http://research.fiu.edu/irb/pages/topaz.html Save often by selecting the "Save" icon at the top of this form since the system does not automatically save your progress.

Alvero, Aaron

Not Submitted

Next Review Date:

Expiration Date:

\section{1}

\section{ADMINISTRATIVE 2}




\section{Reference Number}

This number is system generated.

\section{1}

104175

\section{Protocol Number}

This number will be assigned after the protocol has been processed.

\section{2}

\section{Relation to Another FIU IRB Approved Study}

Is this study related to another FIU IRB approved study under one of the following scenarios? This is a sub-study, which is based off of a larger study (e.g., this study utilizes the data or participants from a larger study); or The former study had a lapse in IRB approval, so the study is being resubmitted as a new original submission submission in order to resume the research.

\section{3}

Yes No

Persons reviewing the information contained herein are reminded of their confidentiality obligations pursuant to the FIU Confidentiality Agreements Policy \#1710.070.

\section{Page Protocol Detail Report Answered}

1 of 15

\section{Questions Only}

Printed By: Alvero, Aaron

10/20/2015 9:46:10 PM 


\section{Page Protocol Detail Report Answered}

\section{2 of 15}

\section{Questions Only}

Printed By: Alvero, Aaron

10/20/2015 9:46:10 PM

\subsubsection{No}

\section{Title}

Provide the title of the project.

\section{4}

Efficacy and Implementation of Automated Scoring Software in Instruction of Literacies to High Level ELLs

\section{Department}

Select the Principal Investigator\&\#39;s department.

\section{5}

COE Teaching and Learning

\section{Principal Investigator}

Provide the name of the Principal Investigator. Students cannot serve as the Principal Investigator. Please Note: Undergraduate/Graduate student research projects are required to have an FIU faculty member with Graduate Faculty Status or Dissertation Advisor Status (DAS) serving as the Principal Investigator. Student researchers need to be listed separately in the "Protocol Associates" section below. Exceptions to this policy may be judged appropriate under particular circumstances and those exceptions shall be determined by the Division of Research.

\section{6}

Dwyer, Eric Eric.Dwyer@fiu.edu

\section{Author}

The Author is the person that is completing this application form. This is typically the same person as the Principal Investigator unless another individual is assisting with the completion of the application form (e.g., Project Coordinator). 


\section{7}

Alvero, Aaron aaronjalvero@gmail.com

\section{Protocol Associates (Not Requiring TOPAZ Access)}

Add all FIU Co-Investigators and FIU Key Associates that will be engaged in this project, but do not need the ability to view/edit the protocol or receive TOPAZ system email notices regarding this protocol. For the "Role" column, designate if the individual is a Co-PI or Key Associate on the project. See the OHRP Engagement Guidance or contact the FIU IRB Office (ORI) for more information on whether someone is considered engaged. For the "Position" column, designate if the individual is a Faculty Member, Staff Member, Undergrad Student, Grad Student, or Post-Doc.

"Responsibilities" might include data entry, recruiting subjects, consenting subjects, etc. Click "Add Row" to add each individual.

\section{9}

\section{First Name Last Name Role Position Department Email Panther ID Responsibilities}

Aaron Alvero Author Masters student TESOL aalve013@fiu.edu 5599182 Lead

\section{External Protocol Associates}

Indicate if there will be any external (non-FIU) Co-Investigators or Key Personnel engaged in this project. Individuals are considered "engaged" if they will be intervening or interacting with human subjects (e.g., consenting subjects, collecting data, etc) and/or accessing coded or identifiable human subject data (e.g., data analysis). See the OHRP Engagement Guidance or contact the FIU IRB Office (ORI) for more information on whether someone is considered engaged.

\subsection{0}

Yes No

Persons reviewing the information contained herein are reminded of their confidentiality obligations pursuant to the FIU Confidentiality Agreements Policy \#1710.070. 


\section{Page Protocol Detail Report Answered}

3 of 15

\section{Questions Only}

Printed By: Alvero, Aaron

10/20/2015 9:46:10 PM

\subsubsection{No}

\section{IRB Educational Training (Attachment)}

All investigators and key personnel that are engaged in conducting research with human subjects are required to complete the web-based Collaborative Institutional Training Initiative Program (CITI) training in the protection of human research subjects. Indicate below if all of the individuals on this project have completed the required CITI IRB training. See the IRB Training web page for more information. Attach the CITI IRB Training Completion Reports. Click the paperclip icon to the right to upload the documents.

\subsection{1}

Yes - CITI IRB Training has been completed by all project personnel. No - CITI IRB Training has not yet been completed by all project personnel. Note: All project personnel must complete the online training prior to the conclusion of the IRB review and approval process. Failure to complete the training will delay the approval process.

\subsubsection{Yes - CITI IRB Training has been completed by all project personnel.}

\section{Conflict of Interest}

Are there any potential financial or other conflicts of interest for any FIU personnel working on this project?

\subsection{2}

Yes FIU employee(s) are required to complete the applicable Faculty Outside Activities and Financial Interest Report available at http://academic.fiu.edu/AcademicBudget/www/downloadforms.htm or the A\&P/USPS Report of Outside Activities form, available at http://hr.fiu.edu/index.php?name=forms_library No

\subsubsection{No}




\section{REVIEW TYPE 3}

\section{Exemption Category Number}

Indicate the Exemption Category Number(s) that you feel would be appropriate for this protocol. The most commonly used categories are Categories \#1, \#2, and \#4. Final determination will be made by the Office of Research Integrity. Note: The detailed Exempt Category Listing is available on the FIU IRB website.

\section{1}

Exemption Category \#1 (Educational Research) Exemption Category \#2 (Educational Tests, Survey Procedures, Interview Procedures or Observation of Public Behavior) Exemption Category \#3 (Educational Tests, Survey Procedures, Interview Procedures or Observation of Public Behavior - Involves Public Officials or Candidates) Exemption Category \#4 (Collection or Study of "Existing" Data, Documents, Records, or Specimens) Exemption Category \#5 (Research and Demonstration Projects with Department or Agency Heads that Study Public Benefit or Service Programs) Exemption Category \#6 (Taste and Food Quality Evaluation and Consumer Acceptance Studies)

\subsubsection{Exemption Category \#1 (Educational Research)}

Persons reviewing the information contained herein are reminded of their confidentiality obligations pursuant to the FIU Confidentiality Agreements Policy \#1710.070. 


\section{Page Protocol Detail Report Answered}

4 of 15

\section{Questions Only}

Printed By: Alvero, Aaron

10/20/2015 9:46:10 PM

\section{Educational Research}

For research proposed under Exemption Category 1, will the research be conducted outside of commonly accepted educational settings or deviate from normal educational practices? If yes, your research will not be eligible for Exempt review.

\subsubsection{1}

Yes Your research will not be eligible for Exempt review. Please stop the completion of this form and proceed with completing the IRB Approval Form (for Expedited / Full Board Review Submissions). No

\subsection{No}

\section{EXEMPTION REQUIREMENTS 4}

\section{Minimal Risks}

Will the research expose participants to discomfort or distress beyond that normally encountered in daily life? If yes, your research will not be eligible for Exempt review.

\section{1}

Yes Your research will not be eligible for Exempt review. Please stop the completion of this form and proceed with completing the IRB Approval Form (for Expedited / Full Board Review Submissions). No

\subsubsection{No}

\section{Risks to Subjects}

Could disclosure of participants' responses outside the research reasonably place participants at risk of criminal or civil liability or be damaging to participants' financial standing, employability, or reputation? If yes, your research will not be eligible for Exempt review.

\section{2}


Yes Your research will not be eligible for Exempt review. Please stop the completion of this form and proceed with completing the IRB Approval Form (for Expedited / Full Board Review Submissions). No

\subsubsection{No}

\section{Deception}

Does any part of the research require deception or incomplete disclosure of information to participants? If yes, your research will not be eligible for Exempt review.

\section{3}

Yes Your research will not be eligible for Exempt review. Please stop the completion of this form and proceed with completing the IRB Approval Form (for Expedited / Full Board Review Submissions). No

\subsubsection{No}

Persons reviewing the information contained herein are reminded of their confidentiality obligations pursuant to the FIU Confidentiality Agreements Policy \#1710.070. 


\section{Page Protocol Detail Report Answered}

\section{5 of 15}

\section{Questions Only}

Printed By: Alvero, Aaron

10/20/2015 9:46:10 PM

\section{Protected Health Information (PHI)}

Will you be accessing, using, or disclosing identifiable protected health information (PHI) from medical records for this research study? For more information, visit the Privacy Practices and HIPAA web page. If yes, your research will not be eligible for Exempt review.

\section{4}

Yes Your research will not be eligible for Exempt review. Please stop the completion of this form and proceed with completing the IRB Approval Form (for Expedited / Full Board Review Submissions). No

\subsubsection{No}

\section{Prisoners}

Will prisoners (or their data and/or specimens) be participants in this research study? If yes, your research will not be eligible for Exempt review.

\section{5}

Yes Your research will not be eligible for Exempt review. Please stop the completion of this form and proceed with completing the IRB Approval Form (for Expedited / Full Board Review Submissions). No

\subsubsection{No}

\section{FDA Regulations}

For research proposed under Exemption Categories 1-5, is the research subject to FDA regulations? If yes, your research will not be eligible for Exempt review.

\section{6}

Yes Your research will not be eligible for Exempt review. Please stop the completion of this form and proceed with completing the IRB Approval Form (for Expedited / Full 
Board Review Submissions). No N/A

\subsubsection{No}

\section{PROJECT OVERVIEW 5}

\section{Project Starting Date}

Provide the date that you are planning to begin the research with human subjects (e.g., date to begin recruitment or access a database). Click the calendar icon below to select your starting date. Please use a future starting date.

\section{1}

$11 / 2 / 2015$

\section{Project Completion Date}

Provide the date that you are planning to finish the research with human subjects (e.g., date that you will be finished with all data analysis). Click the calendar icon below to select your completion date.

\section{2}

$2 / 1 / 2016$

Persons reviewing the information contained herein are reminded of their confidentiality obligations pursuant to the FIU Confidentiality Agreements Policy \#1710.070. 


\section{Page Protocol Detail Report Answered}

6 of 15

\section{Questions Only}

Printed By: Alvero, Aaron

10/20/2015 9:46:10 PM

\section{Funding}

Indicate if funding is (or will be) associated with this project.

\section{3}

Yes No

\subsubsection{No}

\section{Student Research Project}

Is this study being conducted by an FIU student as part of an undergraduate or graduate research project?

\section{4}

Yes No

\subsubsection{Yes}

\section{Type of Student Project (Attachment)}

Select the type of student project that this study falls under. Attach a copy of the five page UGS proposal if the study is part of a Thesis or Dissertation. Click the paperclip icon to the right to upload your document.

\subsubsection{1}

\section{Attachments: UGSThesisProposal.pdf}

Thesis Research

\section{Student Investigator Details}

Provide the following details about the primary student investigator conducting this project.

\subsubsection{2}




\section{First Name Last Name Email Address Phone Number Panther ID}

Aaron Alvero aalve013@fiu.edu 83132007345599182

\section{Type of Project}

Indicate the type of project you will be conducting by selecting the green "+" icon on the right. Select all that apply for this project.

\section{5}

Data Collection Study

\subsubsection{Data Collection Study}

Persons reviewing the information contained herein are reminded of their confidentiality obligations pursuant to the FIU Confidentiality Agreements Policy \#1710.070. 


\section{Page Protocol Detail Report Answered}

\section{7 of 15}

\section{Questions Only}

Printed By: Alvero, Aaron

10/20/2015 9:46:10 PM

\section{Summary of Research}

Summarize the proposed research using non-technical language that can be readily understood by someone outside the discipline. Your summary needs to briefly explain the following information in paragraph format using complete sentences (limit to 300 words): Research design; Procedures to be used; Risks and anticipated benefits; and The importance of the knowledge that may reasonably be expected to result

\section{6}

This project investigates the potential usefulness of automated essay scoring software, computer software programs which provide instant feedback and grades, as a tool for high school students to use in the middle of the writing process instead of as a final assessor. The software is on track to become used as the main grader of writing for high stakes testing despite many of the problems they have presented, especially when it comes to gaming the system. For example, many programs can be tricked into giving a good grade because they look at the surface levels of writing (vocabulary, grammar, variety, and other basic writing features), not the deeper meanings of the words being used. By using that same feedback in the middle of the process instead of the end, students might be able to make more impacting revisions on their final writing drafts. This project will also look at the possibility of increasing the feelings of self-confidence and control over writing needed to be successful. That feeling when discussing literacy and writing is often referred to as efficacy, and because this project encourages students to take more control and to make decisions on their own writing, it could be called self-efficacy. Students are often paranoid of teacher marks and notes on their writing for many reasons, but fear of getting a bad grade and feelings that the teacher does not understand what they are trying to say are consistent notions given by students. By giving what is, according to the makers of AES software, supposed to be feedback based on teacher grading patterns, the goal is to see if using the feedback privately to construct their final drafts can help them make improvements in their writing based on the state 
writing rubric but also increase their self-efficacy in their writing.

\section{Location of Research}

Indicate if the location(s) of the research is domestic or international. Select all that apply.

\section{8}

Domestic Site (United States) International Site (Foreign)

\subsubsection{Domestic Site (United States)}

\section{Domestic Site Details (Attachment)}

Provide the details below for each site/location that will be used in the research study. Examples of tasks done at a site might include activities such as recruitment, consenting, data collection, etc. External (Non-FIU) sites will normally require a letter of support and may also require another IRB\&\#39;s approval if the personnel at that site are engaged in conducting the research. Note: If the research will only take place at FIU, then you should just write "FIU" as the Location Name and then list the Task(s) Done at Site (you do not need to provide FIU\&\#39;s address, city, state and phone number). Click "add row" for each additional site that you need to add. If using an external (non-FIU) site, attach your letter(s) of support and/or external IRB approval letter(s) by clicking the paperclip icon to the right.

\subsubsection{2}

\section{Location Name Address City State Phone Number Task(s) Done at Site}

\section{SUBJECT POPULATION 6}

Persons reviewing the information contained herein are reminded of their confidentiality obligations pursuant to the FIU Confidentiality Agreements Policy \#1710.070. 


\section{Page Protocol Detail Report Answered}

8 of 15

\section{Questions Only}

Printed By: Alvero, Aaron

10/20/2015 9:46:10 PM

\section{Duration of Participation}

Estimate the time required from each participant, including individual interactions, total time commitment, and long-term follow-up, if any.

\section{1}

The project will occur during regular school hours and regular class time; therefore, there will be no additional time commitments for the participants outside of regular school procedures. Each class period meets for one hour and thirty minutes every other day, but variables such as other tests, unforeseen circumstances (school emergencies, for example), and students addressing other in-school obligations (meeting with other teachers, administration, counselors, etc.) make it difficult to give an accurate estimate of the exact amount of time this project will take.

\section{Number of Participants}

The number of participants is defined as the number of individuals who agree to participate even if all do not prove eligible to complete the study. If datasets are being used, then provide the number of datasets that will be accessed.

\section{2}

40

\section{Gender of Subjects}

Indicate the gender of the subjects.

\section{3}

Both

\section{Age of Subjects}

Select the age range(s) of the subjects. Click the green "+" symbol to the right of the screen to make your selection (s). Select all that apply. 
6.4

13-17 Years

18-24 Years

6.4.1 13-17 Years

6.4.2 18-24 Years

Participant Populations

Specify the participant population(s) to be included. Click the green "+" symbol to the right of the screen to select the populations. Select all that apply.

6.5

Children $(<18$ years $)$

Students

6.5.1 Children $(<18$ years)

\subsubsection{Students}

Persons reviewing the information contained herein are reminded of their confidentiality obligations pursuant to the FIU Confidentiality Agreements Policy \#1710.070. 


\section{Page Protocol Detail Report Answered}

9 of 15

\section{Questions Only}

Printed By: Alvero, Aaron

10/20/2015 9:46:10 PM

\section{Other Populations}

If you chose "Other" in the previous question, please indicate the other population below. Otherwise, put "N/A" for your response.

\section{6}

N/A

\section{Inclusion \& Exclusion Criteria}

Indicate if you will be including and/or excluding individuals based on a specific set of criteria for this project. Provide a justification for the inclusion and/or exclusion criteria.

\section{7}

The focus of the study are high level ESOL students (levels 3-5), anyone below that will not be included. Also, all of my students are at level 3 and above.

\section{SUBJECT RECRUITMENT 7}

\section{Identification of Subjects}

Describe how potential participants will be identified (e.g., individuals known to investigator, record review, etc.). Explain how investigator(s) will gain access to this population, as applicable.

\section{1}

As their teacher of record for "Speech 1" (a high school composition course), I have access to all of their basic information, including their ESOL level. One of my classes is made up entirely of ESOL students, and the other participants were gleaned from my student database.

\section{Recruitment/Advertising Process (Attachment)}

Describe the recruitment process; including the setting in which recruitment will take place. Describe the types of advertisements that will be used (e.g., ads, flyers, website postings, recruitment letters, and/or oral written scripts). Explain how the process 
respects potential participants\&\#39; privacy. Attach copies of the proposed recruitment materials. Click the paperclip icon to the right to upload your document(s).

\section{2}

The students were placed in my class during the summer, eliminating the need for extra recruitment or advertising.

\section{Participant Compensation or Incentives}

Indicate if participants will receive compensation or other incentives to participate in the research study.

\section{3}

Yes No

\subsubsection{No}

\section{METHODS \& ACTIVITIES 8}

Persons reviewing the information contained herein are reminded of their confidentiality obligations pursuant to the FIU Confidentiality Agreements Policy \#1710.070. 


\section{Page Protocol Detail Report Answered}

10 of 15

\section{Questions Only}

Printed By: Alvero, Aaron

10/20/2015 9:46:10 PM

\section{Explanation of Methods \& Activities (Attachment)}

Identify and describe all interactions that are to be performed solely for the research study. Explain the methods and procedures to be followed with an emphasis on implications for subjects\&\#39; experiences. Describe data to be collected and data analysis. List the names of the different data collection forms that you will be using if conducting surveys, interviews, and/or focus groups. Attach data collection forms to be used by clicking on the paperclip icon to the right.

\section{1}

\section{Attachments: StudentWritingSurvey.docx ParentalConsent(1).docx ArgumentationRubric_6-11_Final2.pdf InformationalRubric_6-11_Final.pdf}

The writing rubrics which will be used to determine whether or not the student writing improved using AES software have two categories: argumentative and informative. Both categories are the same except that the argumentative rubric calls students to write with a sustained claim; the informative rubric calls for students to present information while sustaining a main idea, not taking a position on either side of the issue. The highest possible grade is ten and the lowest possible grade is zero, oftentimes used for essays which are completely off-topic (either due to misunderstanding the prompt or the basic academic writing style required to pass). The essay will be done based on the regular class routine as dictated by the district pacing guide. The dependent variable will be the writing scores after using the AES program in the middle of the writing process. After that, the students will complete a survey which is designed to measure their opinions on the software as well as their feelings of self-efficacy in their writing.

\section{Types of Activities}

Carefully identify all of the activities that will be involved in the research by clicking on the green "+" icon to the right. Identify ALL that apply to the research.

\section{2}


Data Analysis (Not Publicly Available)

Educational Tests

Surveys or Interviews (Individual)

Program Evaluation

Observation of Participants

\subsubsection{Data Analysis (Not Publicly Available)}

\subsubsection{Educational Tests}

\subsubsection{Surveys or Interviews (Individual)}

\subsubsection{Program Evaluation}

\subsubsection{Observation of Participants}

Persons reviewing the information contained herein are reminded of their confidentiality obligations pursuant to the FIU Confidentiality Agreements Policy \#1710.070. 


\title{
APPENDIX B
}

\section{FIII Education}

\author{
PARENTAL CONSENT TO PARTICIPATE IN A RESEARCH STUDY \\ Technology in the Writing Class
}

\section{PURPOSE OF THE STUDY}

You are being asked to give your permission for your child to be in a research study. The purpose of this study is to see if technology can improve the writing of high school students.

\section{NUMBER OF STUDY PARTICIPANTS}

If you agree to allow your child to participate in this study, he/she will be one of 35 people in this research study.

\section{DURATION OF THE STUDY}

Your child's participation will require three weeks during class time.

\section{PROCEDURES}

If your child participates in this study, we will ask your child to do the following things: 1. The student will submit their writing to a software program that gives feedback about the writing before submitting it to the teacher,

2. Writing class will go on as usual, but instead of writing and submitting their work directly to the teacher, the student will submit it to a software program first. The student will be able to look at the feedback and determine which parts of it they agree with and want to include in their writing.

\section{RISKS AND/OR DISCOMFORTS}

There are no known risks, as this will all be part of regular class time and students will not lose instruction.

\section{BENEFITS}

Students might be able to not only improve their writing but feel more confident about their skills and not worry about the grades associated with teacher feedback.

\section{ALTERNATIVES}

There are no known alternatives available to your child other than not taking part in this study. If the student is not allowed to participate, they will skip the technology step. 


\section{CONFIDENTIALITY}

The records of this study will be kept private and will be protected to the fullest extent provided by law. In any sort of report we might publish, we will not include any information that will make it possible to identify your child as a subject. Research records will be stored securely and only the researcher will have access to the records. However, your child's records may be reviewed for audit purposes by authorized University or other agents who will be bound by the same provisions of confidentiality.

\section{COMPENSATION \& COSTS}

Your child will receive a class participation grades worth one day of work for their participation. Your child will not be responsible for any costs to participate in this study.

\section{RIGHT TO DECLINE OR WITHDRAW}

Your child's participation in this study is voluntary. Your child is free to participate in the study or withdraw his/her consent at any time during the study. Your child's withdrawal or lack of participation will not affect any benefits to which he/she is otherwise entitled. The investigator reserves the right to remove your child from the study without your consent at such time that they feel it is in the best interest.

\section{RESEARCHER CONTACT INFORMATION}

If you have any questions about the purpose, procedures, or any other issues relating to this research study you may contact AJ Alvero at 831-320-0734 or aaronjalvero@dadeschools.net

\section{IRB CONTACT INFORMATION}

If you would like to talk with someone about your child's rights of being a subject in this research study or about ethical issues with this research study, you may contact the FIU Office of Research Integrity by phone at 305-348-2494 or by email at ori@fiu.edu.

\section{PARTICIPANT AGREEMENT}

I have read the information in this consent form and agree to allow my child to participate in this study. I have had a chance to ask any questions I have about this study, and they have been answered for me. I understand that I will be given a copy of this form for my records.

Signature of Parent/Guardian

Printed Name of Parent/ Guardian

Printed Name of Child Participant

Signature of Person Obtaining Consent
Date

Date 
VITA

\section{AARON JORDAN ALVERO}

Stanford University, $\mathrm{PhD}$ in Curriculum and Teacher

Education, Specialization in Literacy, Language, and

English Education

2016

Florida International University, MS in TESOL, 2016

Thesis: Efficacy and Implementation of Automated Essay

Scoring Software in Instruction of Literacies to High Level ELLs

2012

University of Miami, BA in English, 2012

Modern Languages Minor (Spanish and Haitian Creole); 3.70

Major GPA; Dean's List

Florida Certified English 6-12 Teacher, ESOL Endorsement (DOE \#1232277) Third highest TeacherMatch score in Miami-Dade County

2013-Present

Miami-Dade County Public Schools

High School English/Language Arts Teacher

Claes Nobel Educator of Distinction (National

Society of High School Scholars)

National Merit and Florida Bright Futures

Scholarships after-school tutor

Increased approximately $90 \%$ of juniors from level 1

to levels 2-4 (FCAT Reading 2.0)

Connected students with internships, career explorer, and college preparation programs

Brought the "bottom 25\%" of sophomores up to state averages $(+55 \%$ passing) in writing

Literacy Interventionist

Taught literacy skills to small groups (mainstream or ESOL) with differentiated instruction

School finished top 5 in the district in FCAT Writes (state writing assessment)

Nov. 2013-Present

Varsity Tutors

Tutored students and alumni from South Florida private schools, public schools, and universities 
Specialized in literacy, standardized tests (ACT, SAT, and GRE), study skills, and Spanish

Helped 7th grader earn 580 in Writing Section (9 on the essay) and 520 in Reading Section of SAT

Oct. 2011-Feb. 2012 Cuban Heritage Collection at the University of Miami

Archival Maintenance, Materials Recovery, Incoming Collections Cataloguing

Retrieved materials from the archives for patrons

Documented incoming donations/collections for archival and future exhibits

2008-Present

Private Writing and Editorial Consultant (2008-Present) Edited $\sim 55$ pages from a book written by a former professor at the University of Miami

Proofread/edited scholarly articles for a German PhD candidate for publications and presentations

Edited a scholarly article for publication in a journal written by doctors and medical students Consulted medical school application essays, scholarship essays, and business letters Guided essays on art history, philosophy, engineering, English, business, and other subjects

Projects and Summer Work

Caribbean Studies Association 2016 International Conference Panelist, "The quest for Kreyòl epistemologies through language immersion"

University of Miami School of Law STREET Law Program Connected STREET Law program to Miami Central to bring legal education to secondary students

Literary Magazine Sponsor and Chess Club Co-Sponsor Sponsored students making a literary magazine; helped Chess Club place in local tournaments

South Florida Education Research Conference 2016 Proposal Reviewer

TESOL International Conference 2016, 2017 Proposal Reviewer

Reviewed and rated proposals for presentations to be conducted at the conferences 
Summer 2015

FLAS Fellowship: Haitian Summer Institute at FIU

Took four weeks of intensive Haitian Creole classes and spent two weeks touring Haiti

June-July 2014 Rider University Study Tours at Barry University

Intensive English Instructor

Led three hour lessons based on Miami for English

learners from across the globe

Assessed deficiencies and strengths in order to collect data and evaluate needs of class

Stanford Enhancing Diversity in Graduate Education Fellowship $(\$ 12,800)$

FLAS Summer Fellowship at the Haitian Summer Institute $(\$ 7,500)$

Madeline Kitts Scholarship (\$5,000)

FIU Graduate Grant $(\$ 5,000)$ TEACH Grant $(\$ 4,000)$

Bellsouth Education Scholarship $(\$ 3,000)$

Latin American and Caribbean Center Scholarship (\$500) Hispanic Scholarship

Fund

Fluent Spanish; Fluent Haitian Creole; Basic Japanese (written and spoken)

TESOL International

National Council of Teachers of English

Phi Delta Kappa

NAACP 